\title{
Photoacoustic hygrometer for icing wind tunnel water content measurement: design, analysis, and intercomparison
}

\author{
Benjamin Lang ${ }^{1,2,3}$, Wolfgang Breitfuss ${ }^{4}$, Simon Schweighart ${ }^{2}$, Philipp Breitegger ${ }^{1}$, Hugo Pervier ${ }^{5}$, \\ Andreas Tramposch ${ }^{2}$, Andreas Klug ${ }^{3}$, Wolfgang Hassler ${ }^{2}$, and Alexander Bergmann ${ }^{1}$ \\ ${ }^{1}$ Graz University of Technology, Institute of Electrical Measurement and Sensor Systems, Graz, Austria \\ ${ }^{2}$ FH JOANNEUM GmbH, Institute of Aviation, Graz, Austria \\ ${ }^{3}$ AVL List GmbH, Nanophysics \& Sensor Technologies, Graz, Austria \\ ${ }^{4}$ RTA Rail Tec Arsenal Fahrzeugversuchsanlage GmbH, Vienna, Austria \\ ${ }^{5}$ Cranfield University, School of Aerospace, Transport and Manufacturing, Cranfield, United Kingdom
}

Correspondence: B. Lang (benjamin.lang@tugraz.at)

Received: 21 July 2020 - Discussion started: 8 September 2020

Revised: 15 January 2021 - Accepted: 26 January 2021 - Published: 31 March 2021

\begin{abstract}
This work describes the latest design, calibration and application of a near-infrared laser diode-based photoacoustic (PA) hygrometer developed for total water content measurement in simulated atmospheric freezing precipitation and high ice water content conditions with relevance in fundamental icing research, aviation testing, and certification. The single-wavelength and single-pass PA absorption cell is calibrated for molar water vapor fractions with a two-pressure humidity generator integrated into the instrument. Laboratory calibration showed an estimated measurement accuracy better than $3.3 \%$ in the water vapor mole fraction range of 510-12360 ppm (5\% from 250-21 $200 \mathrm{ppm}$ ) with a theoretical limit of detection $(3 \sigma)$ of $3.2 \mathrm{ppm}$. The hygrometer is examined in combination with a basic isokinetic evaporator probe (IKP) and sampling system designed for icing wind tunnel applications, for which a general description of total condensed water content (CWC) measurements and uncertainties are presented. Despite the current limitation of the IKP to a hydrometeor mass flux below $90 \mathrm{~g} \mathrm{~m}^{-2} \mathrm{~s}^{-1}$, a CWC measurement accuracy better than $20 \%$ is achieved by the instrument above a CWC of $0.14 \mathrm{~g} \mathrm{~m}^{-3}$ in cold air $\left(-30^{\circ} \mathrm{C}\right)$ with suitable background humidity measurement. Results of a comparison to the Cranfield University IKP instrument in freezing drizzle and rain show a CWC agreement of the two instruments within $20 \%$, which demonstrates the potential of PA hygrometers for water content measurement in atmospheric icing conditions.
\end{abstract}

\section{Introduction}

Atmospheric water in the form of clouds and precipitation is of particular concern to aviation at temperatures below freezing, as supercooled liquid water and ice crystal environments present potentially hazardous conditions to aircraft, leading to airframe and air data probe icing (Vukits, 2002; Gent et al., 2000) or in-flight engine power loss (Mason et al., 2006).

Freezing precipitation containing supercooled large drops (SLDs) with drop diameters in excess of $50 \mu \mathrm{m}$ and convective mixed-phase and glaciated clouds with high mass concentrations of ice crystals, i.e., ice water content (IWC) up to several grams per cubic meter, constitute two particular meteorological environments associated with severe icing events (Politovich, 1989; Bernstein et al., 2000; Cober et al., 2001b; Riley, 1998).

SLD icing environments of freezing drizzle (maximum drop diameters from 100 to $500 \mu \mathrm{m}$ ) or freezing rain (max. diameters greater than $500 \mu \mathrm{m}$ ), as classified for the certification of large transport aircraft, are comprehensively characterized by envelopes of liquid water content (LWC), temperature, pressure altitude, drop size distributions, and horizontal extent in Appendix $\mathrm{O}$ of the European Aviation Safety Agency Certification Specifications 25 (EASA CS-25, 2020) and the Code of Federal Regulations Title 14 Part 25 (FAA CFR-25, 2019). Mixed-phase and ice crystal environments are likewise covered with a total condensed water content 
envelope by Appendix P and D of the two documents, respectively.

Replication of the full SLD, mixed-phase, or high IWC condition envelopes in icing wind tunnels (IWTs) has been largely accomplished by organizations devoted to the experimental simulation of icing environments for the purpose of fundamental icing research and certification of aeronautical components but is associated with a lack of appropriate instrumentation and is still a work in progress for some conditions (Orchard et al., 2018; Van Zante et al., 2018; Bansmer et al., 2018; Breitfuss et al., 2019; Chalmers et al., 2019).

The accuracy and reliability of conventional water content instrumentation in the conditions encompassed by Appendix $\mathrm{O}$ and $\mathrm{P} / \mathrm{D}$ is an issue frequently addressed for inflight and IWT characterization (Strapp et al., 2003; Korolev et al., 2013; Orchard et al., 2019). Conventional instrumentation in this context refers to ice accretion blades or cylinders for LWC measurement and evaporating (multi-element) hotwire sensors used for simultaneous LWC and total condensed water content $\left(\mathrm{CWC} ;{ }^{1}\right.$ combined LWC and IWC) measurements. Both methods are either known or suspected to suffer from size- and water-content-dependent inaccuracies in large drop or ice crystal icing environments due to uncertainties in collection efficiency and mass losses before accretion or evaporation (Cober et al., 2001a; Strapp et al., 2003; Emery et al., 2004; Isaac et al., 2006; Korolev et al., 2013; Steen et al., 2016).

This situation has led to the development of new benchmark isokinetic evaporator probe (IKP) instruments for CWC measurement (Davison et al., 2008; Strapp et al., 2016), regarded as closest to a first principles measurement and primarily designed for and deployed in the characterization of high IWC mixed-phase and glaciated conditions (e.g., Ratvasky et al., 2019). IKPs are used to extractively sample droplets and ice crystals in the icing environment with a forward-facing, isokinetically operated inlet. After sampling, hydrometeors are evaporated to measure the combined condensed and ambient air water content with a suitable hygrometer. Ambient air background water vapor (BWV) is measured separately and subtracted from the total water content (TWC) to derive the condensed water content. Measurement of the BWV concentration is usually accomplished via a second, backward-facing inlet connected to another hygrometer. Due to the isokinetic sampling, losses of droplets or particles by re-entrainment into the flow after entering a sufficiently long inlet are improbable. Hence, IKP particle size distribution dependence is in theory only governed by the aspiration efficiency of the inlet.

Collectively, only few such reference instruments for CWC measurement in icing conditions similar to Appendix $\mathrm{O}$ and $\mathrm{P} / \mathrm{D}$ currently exist. This lack of instrumen-

\footnotetext{
${ }^{1}$ Often abbreviated as TWC. To provide a clear distinction to total water content, we adhere to the nomenclature and reasoning given by Dorsi et al. (2014).
}

tation has motivated the development of the hygrometer and sampling system described in this work.

Hygrometers in devices specifically designed for IWT operation typically apply commercially available nondispersive infrared (NDIR) gas analyzers based on optical absorption spectroscopy (e.g., Strapp et al., 2016; Bansmer et al., 2018, Sect. 4.3). The upper end of water content that has to be within the range of suitable hygrometers is given by the combined background and condensed water content in the measurement environment. The former is approximately limited to fully saturated air at a static air temperature (SAT) of $0^{\circ} \mathrm{C}$, and the latter may be taken as an upper bound of $10 \mathrm{~g} \mathrm{~m}^{-3}$ to the peak CWC of $9 \mathrm{~g} \mathrm{~m}^{-3}$ in high IWC conditions (EASA CS-25, 2020). This may add up to molar water vapor fractions of $18500 \mathrm{ppm}$ at standard pressure $(1000 \mathrm{hPa})$. Accuracy requirements are primarily determined by high BWV concentrations that have to be subtracted from high total water concentrations at low CWC and high ambient temperatures (Davison et al., 2016). The necessary hygrometer limit of detection highly depends on the specific measurement conditions but may be estimated from the fact that detection of a CWC of $0.05 \mathrm{~g} \mathrm{~m}^{-3}$ in dry air at standard pressure requires an accuracy and limit of detection better than $48 \mathrm{ppm}$.

With the measurement system described in detail by Szakáll et al. (2001), Tátrai et al. (2015) have first demonstrated the suitable accuracy of photoacoustic (PA) hygrometers in and beyond the above measurement range. Compared to NDIR sensors, photoacoustic spectroscopy offers the potential of achieving higher signal-to-noise ratios (SNRs) with equal response time, while providing high selectivity and high robustness due to the possibility of optical single-pass arrangements and an instrument response that is invariant to the total absorption pathlength (Hodgkinson and Tatam, 2013).

In this work we describe the latest design, preliminary calibration, and basic properties of a new PA hygrometer and two-pressure humidity generator, developed with the goal of providing the total water measurement and calibration ranges typical for simulated atmospheric icing conditions applied in aviation testing and certification. The hygrometer is examined in combination with a basic IKP and sampling system, designed for IWT application in Appendix O conditions, for which a description of CWC measurement and its associated uncertainties are presented. Finally, results of water content measurements in freezing drizzle and rain conditions in a closed-circuit IWT, calibrated according to SAE Aerospace Recommended Practices (SAE ARP-5905, 2015), are presented and compared to measurements with a reference IKP and a hot-wire instrument. 


\section{Instrument design}

A schematic overview of the entire instrument is shown in Fig. 1a. The system consists of a sampling probe positioned inside the icing wind tunnel and a measurement and sampling unit integrated into a 19 inch rack, positioned outside the tunnel and connected by $7 \mathrm{~m}$ long heated and thermally insulated PTFE tubing, temperature-controlled to the measurement temperature of $35^{\circ} \mathrm{C}$ to prohibit condensation. The probe is a total water (TW) sampling probe operated isoaxially and near isokinetic conditions, which also features a second inlet port intended for BWV measurement. Hydrometeors entering the forward-facing TW inlet are evaporated inside the probe, enriching simultaneously sampled ambient air with the evaporated condensed water.

The sampling system is designed to provide five main operating modes:

\section{TW measurement (path 1 in Fig. 1a)}

\section{BWV measurement (path 2)}

3. zeroing (PA background signal measurement; path 3)

4. calibration (path 4)

5. inlet purging (path 3 combined with path 1 or 2).

For TW and BWV measurement, air sampled through the respective inlet is continuously pumped to the measurement unit, where the PA hygrometer (PA cell) is used to measure the water vapor mole fraction in parts of the TW or the full BWV inlet air flow. Currently, only a single hygrometer has been implemented and humidity measurement may only be alternated between TW and BWV measurement.

During isokinetic TW sampling, the majority of the flow bypasses the hygrometer (path 5 in Fig. 1a) to the scroll pump (Edwards, nXDS10iC). The hygrometer is supplied by a constant standard volumetric flow rate of 0.75(4) standard $\mathrm{L} \mathrm{min}^{-1}$ (slpm; reference conditions: $273.15 \mathrm{~K}$ and $1013.25 \mathrm{hPa}$ ), set by a pressure controller (Vögtlin Instruments, GSP-B9SA-BF26) upstream the cell and a critical orifice of $350 \mu \mathrm{m}$ nominal diameter downstream the cell. A calibrated mass flow controller (MFC; Vögtlin Instruments, GSC-C9SA-FF12) is used to control the bypass flow rate and a calibrated flowmeter included in the pressure controller measures the actual hygrometer flow rate. Isokinetic sampling at the TW inlet is set by adjusting the MFC flow rate to a combined flow rate matching the isokinetic conditions, which are calculated using the IWT test section operating parameters and TW inlet geometry parameters (cf. Sect. 4).

The instrument features a two-pressure humidity generator also integrated into the rack, which in combination with zero air is used for calibration and zeroing of the hygrometer. Control of flow, temperature, and pressure, together with signal processing and data logging for the sampling system and humidity generator, is performed with a dedicated embedded system (National Instruments, NI cRIO 9063).
In the following subsections, the major components of the instrument are described in further detail.

\subsection{Photoacoustic hygrometer}

The hygrometer is a custom-built single-cell photoacoustic absorption spectrometer, providing a signal proportional to the water vapor number concentration in the total water or background water air stream. Figure $1 \mathrm{~b}$ presents a schematic of the PA cell together with the optic configuration and electronic setup.

A fiber-coupled distributed feedback laser diode (NEL, NLK1E5GAAA) is intensity modulated at approximately $4584 \mathrm{~Hz}$ (at $35^{\circ} \mathrm{C}$ ) to excite the fundamental acoustic resonance mode of the PA cell when water vapor is present. The diode is temperature-controlled to the peak of a ro-vibrational water vapor transition at $1364.68 \mathrm{~nm}$ $\left(7327.68 \mathrm{~cm}^{-1} ; 296 \mathrm{~K}\right)$, which was chosen based on HITRAN simulations (Gordon et al., 2017) as it exhibits the highest spectral line intensity in the $1.38 \mu \mathrm{m}$ absorption band $\left(1.86 \times 10^{-20} \mathrm{~cm} \mathrm{molec}^{-1}\right)$ and low interference from other anticipated atmospheric constituents. At the PA cell operating conditions ( $308 \mathrm{~K}, 800 \mathrm{hPa}$ ) and low water vapor concentrations, the selected line has a maximum absorption cross section of $8.01 \times 10^{-20} \mathrm{~cm}^{2} \mathrm{molec}^{-1}$. This is similar to and higher than the cross sections around 1368.6 and $1392.5 \mathrm{~nm}$, respectively $\left(8.09 \times 10^{-20}\right.$ and $5.99 \times 10^{-20} \mathrm{~cm}^{2}$ molec $\left.^{-1}\right)$, two regions that have been targeted in previous photoacoustic water vapor sensing applications (e.g., Besson et al., 2006; Kosterev et al., 2006; Tátrai et al., 2015). Intensity modulation is performed by square wave modulating the applied laser current at the resonance frequency from the maximum permissible laser diode current down to just below the lasing threshold with a benchtop laser driver (Thorlabs, ITC4001), maintaining an average optical power of 9.9(1) $\mathrm{mW}$. Square wave rather than sinusoidal modulation was applied, as a higher signal amplitude is theoretically expected for the former (e.g., Szakáll et al., 2009). Modulation of the laser current to just below the threshold current resulted in maximized photoacoustic signal amplitudes. It should be noted that modulation to slightly above the threshold current may be advantageous for practical reasons (Bozóki et al., 2011). The laser beam is collimated to a diameter of $2 \mathrm{~mm}$ and directed through the resonator via two N-BK7 Brewster windows angled at $56.4^{\circ}$. A thermal power meter (Thorlabs, PM16-401) is used to measure average optical power when the cell is flushed with zero air during PA background signal measurements. Monitoring of the laser power during measurements is accomplished by a fiber splitter with a $99: 1$ split ratio (Thorlabs, TW1300R1A1) in combination with a temperaturecontrolled InAsSb photodetector (Thorlabs, PDA10PT-EC). However, the high wavelength and output power stability of the laser diode allows stable operation over the duration of typical measurement series, thus no wavelength locking on the absorption line or power correction is applied on mea- 
(a)

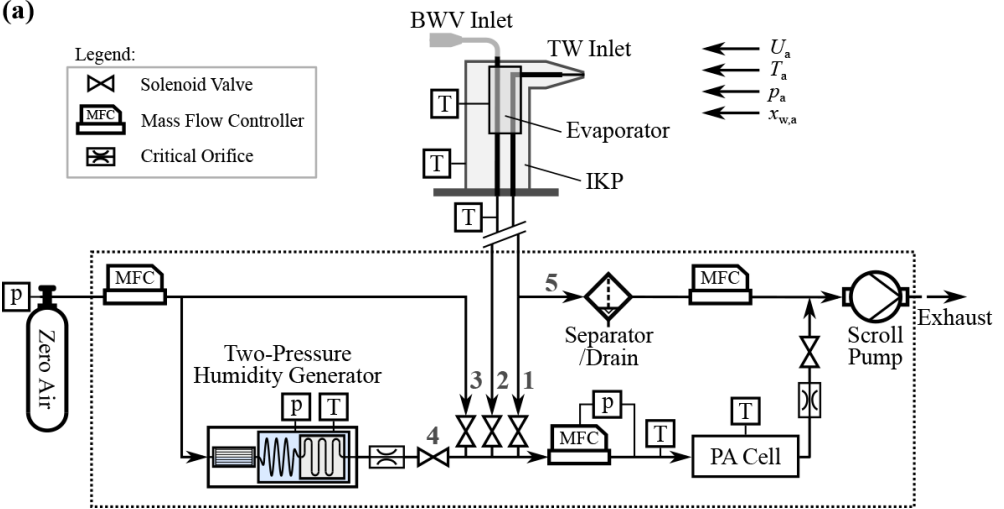

(b)

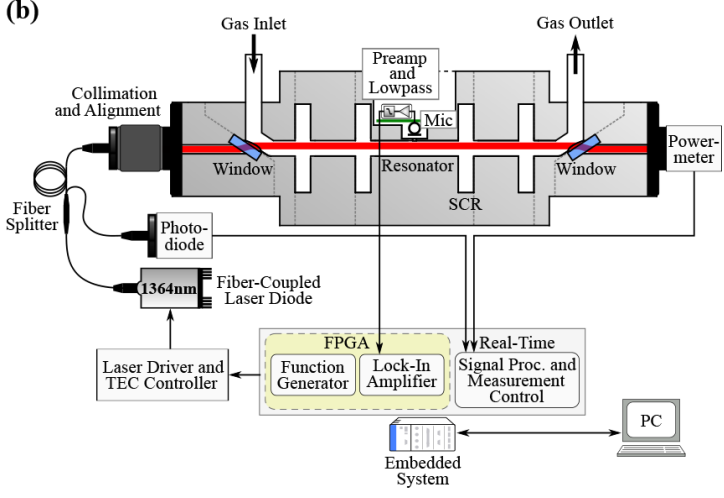

Figure 1. (a) Schematic of the instrument showing the isokinetic evaporator probe (IKP) and the measurement (PA cell), sampling, and calibration system (two-pressure humidity generator and zero air). Locations of temperature and pressure control are indicated by $(T)$ and $(p)$, respectively. Indicated numbers enumerate the individual flow paths. The rearward-facing BWV probe indicates the extension of the BWV inlet port not applied in this work. (b) Schematic of the photoacoustic cell together with the optical and the electronic setup, showing the control, data acquisition, and signal processing performed on the real-time embedded system.

sured signals in between calibration cycles. The two outermost volumes of the PA cell, on the left-hand side enclosed by the optical collimation unit and the Brewster window, are filled with ambient air and are sealed by gaskets and PTFE thread seal tape. Attenuation of the laser optical power due to absorption from water vapor in these volumes remained constant within the above stated bounds of the optical power in between calibrations.

Measurement air is pumped through the stainless steel PA cell via milled $6 \mathrm{~mm}$ inner diameter (ID) cylindrical ducts. At the center of the modularly designed cell a $34 \mathrm{~mm}$ long cylindrical resonator is formed by a termination on either side with two acoustically short concentric resonators (Selamet and Radavich, 1997). Short concentric resonators are used instead of larger expansion chambers (buffer volumes) to decrease gas exchange and measurement response time (cf. Sect. 3.1). The diameters and distances in between the small volume acoustic band-stop filters are tuned to maximize the resonator quality factor $(Q=17)$, while minimizing transmission of external noise into the cell. At the center of the resonator and the location of the antinode of the fundamental longitudinal resonance mode, an electret condenser microphone (Knowles, EK-23028) is connected in a small volume gas- and noise-tight enclosure to measure the PA pressure signal.

The PA cell is operated at constant temperature, pressure, and flow to maintain a microphone sensitivity and resonance frequency independent of ambient and IWT conditions.

The temperature of the thermally insulated PA cell is controlled to $35.0(3){ }^{\circ} \mathrm{C}$ by two integrated heating cartridges to stabilize resonance frequency and microphone sensitivity. ${ }^{2}$ An additional resistance temperature detector (RTD),

\footnotetext{
${ }^{2}$ The number in parenthesis gives the half-width of the rectangular confidence interval in terms of the last digit.
}

installed in the sampling gas stream approximately $100 \mathrm{~mm}$ upstream of the cell, is used to control the gas temperature to $35.0(3){ }^{\circ} \mathrm{C}$ inside the PA cell by controlling the heating of the upstream tubing in the measurement unit. This temperature also sets the theoretical upper water vapor mole fraction measurement limit of 58600 ppm before condensation of water vapor in the sampling lines and the PA cell occurs.

Although the sampling system and the IKP are designed to operate around standard pressure, the PA cell pressure may be set with the pressure controller upstream of the hygrometer within the limits given by the pressure loss of the upstream flow elements down to $100 \mathrm{hPa}$. The sensitivity of the PA hygrometer, however, is maximized towards higher cell pressures (cf. Appendix A). For IWT measurement, the cell pressure is set to $800(8) \mathrm{hPa}$, close to the pressure of optimal signal-to-noise ratio (SNR) at approximately $850 \mathrm{hPa}$ (cf. Fig. A1). A lower than optimum cell pressure was used during measurements to allow for the occurring head loss at high IWT airspeeds and TW sampling flow rates. To further decrease signal noise, the PA cell is vibrationally decoupled from the scroll pump mounted in the rack by a vibrationabsorbing mount and short sections of PTFE tubing at the gas in- and outlet of the cell.

Laser current control, signal processing, and data logging of microphone and power monitoring signals is carried out with a second dedicated embedded system (National Instruments, NI cRIO 9031), a real-time processor combined with a reconfigurable field programmable gate array (FPGA). The laser current modulation signal is generated by a function generator implemented on the FPGA. Data acquisition of the microphone signal after analog amplification with a transimpedance amplifier (10-fold gain), together with the photodetector signal, is carried out with a 24 bit ADC (National Instruments, NI 9234) at a sampling rate of $52.1 \mathrm{kHz}$. A digital dual-phase lock-in amplifier implemented on the FPGA is 
used to determine in-phase and quadrature components of the microphone signal at the frequency of modulation. The lockin signal amplitude (referred to as PA signal) used to derive the water vapor mole fraction is calculated and logged on the real-time operating system with a $10 \mathrm{~Hz}$ rate after phasecorrect background signal correction (cf. Appendix B).

Despite operation at controlled measurement conditions, the hygrometer sensitivity is a function of the measured water content for several reasons. Increasing water content causes decreasing irradiance along the absorption path (Beer-Lambert law) and therefore reduce sensitivity. In addition, the electret microphone sensitivity is a function of humidity (specified $0.02 \mathrm{~dB} \% \mathrm{RH}^{-1}$; Langridge et al., 2013). Furthermore, speed of sound and therefore resonator resonance frequency is a function of humidity (Zuckerwar, 2002). Shifts in resonance frequency may reduce effective resonator amplification and sensitivity according to the approximately Lorentzian resonator frequency response, if the frequency of modulation is not shifted accordingly (Szakáll et al., 2009). Finally, photoacoustic conversion efficiency (i.e., conversion of absorbed laser radiation to a detectable pressure signal) for water vapor in air is concentration dependent and over the range of typical atmospheric concentrations and pressures varies by a factor of five (Lang et al., 2020).

All of the above effects are to a great extent accounted for by calibrating the hygrometer over the range of expected water vapor concentrations and by applying a suitable nonlinear calibration function, which is described in greater detail in Lang et al. (2020). The PA signal reduction associated with resonance frequency humidity dependence $(0.5 \%$ for the $14 \mathrm{~Hz}$ shift from 0 to $20000 \mathrm{ppm}$ ) is taken into account by maintaining the laser modulation frequency at the dry air resonance frequency $\left(4584 \mathrm{~Hz}\right.$ at $\left.35^{\circ} \mathrm{C}\right)$ for calibration and measurements. This method results in maximum amplification and PA signal at low concentrations. The approximately quadratic sensitivity loss for higher concentrations is considered in the second-order term of the calibration function.

\subsection{Calibration unit}

Determination of the water vapor concentration from the hygrometer signal requires background signal correction (zeroing) and calibration with known concentrations of water vapor. The system is calibrated by generating and providing a stable flow of humidified air with known molar fractions of water vapor to the inlet of the hygrometer (e.g., Dorsi et al., 2014; Tátrai et al., 2015). This approach is preferred to the method of introducing a continuous stream of liquid water or ice into the TW inlet and calibrating for CWC (e.g., Strapp et al., 2016), as calibration may be performed during IWT operation without removing the sampling probe. With the goal of performing calibration over a major part of the necessary water content range within a short time, a compact custom-made two-pressure humidity generator $(\mathrm{HG})$ was in- tegrated into the instrument. Two-pressure humidity generation offers the benefit of enabling rapid and accurate setting of a wide range of humidity levels in a saturation chamber at a convenient and constant temperature by varying the pressure and thus the molar water vapor fraction (Wernecke and Wernecke, 2013).

Zeroing of the instrument is performed by acquiring a PA background signal after continuously flushing the PA cell with zero air from an external gas cylinder (Messer, scientific grade synthetic air; residual water volume fraction below 2 ppmv) until a stable reading is attained (approx. $20 \mathrm{~min}$ ).

For calibration, zero air is initially humidified in a presaturation stage, i.e., a porous ceramic with honeycomb structure (IBIDEN Ceram) in a room temperature water bath, to a dew point well above the main saturation chamber dew point. The humidified air is subsequently passed through a lower temperature and pressure-controlled $1 \mathrm{~m}$ long coiled tube heat exchanger and the main saturator, where the air is saturated with respect to the local temperature and pressure.

The saturator is a $(6 \times 25 \times 600) \mathrm{mm}$ (width $\times$ height $\times$ length) channel milled into a stainless steel block, hermetically sealed and partially filled with distilled water. Both the heat exchanger and saturator are placed in a stirred and thermally insulated water bath, temperature-controlled by thermoelectric coolers within the range of $1{ }^{\circ} \mathrm{C}$ to ambient temperature. Saturator air pressure is controlled within the range of 1000 to $8000 \mathrm{hPa}$ with an MFC (Vögtlin Instruments, GSC-C9SA-FF12) upstream of the HG. By increasing the saturator pressure to its maximum value, the $1000 \mathrm{hPa}$ water vapor saturation fraction may be reduced by a ratio of $1: 7.8$.

Bath temperature and saturator air pressure are measured with a high-precision four-wire Pt100 (Omega Engineering, P-M-1/10-1/8-6-0-PS-3) combined with a calibrated 24-Bit ADC (National Instruments, NI 9217) and a calibrated pressure transducer (KELLER AG, PAA 33X), traceable to NIST and Swiss national standards, respectively. Associated measurement uncertainties are given in Table E1. The molar water vapor saturation fraction, which remains constant during expansion to the lower pressure level of the hygrometer, is calculated from the measured saturation temperature and pressure according to Wagner and Pruss (1993) and Greenspan (1976).

In the described configuration, the operational range of the $\mathrm{HG}$ extends from $845 \mathrm{ppm}$ to approximately $22000 \mathrm{ppm}$ (maximum saturator temperature of $19^{\circ} \mathrm{C}$ ). Two saturator temperature set points are used for calibration, covering the full humidity range by varying the saturator pressure. The settling time to a stationary hygrometer signal after changes in the HG settings is below $7 \mathrm{~min}$. This figure is mainly determined by the relatively low signal noise of the PA hygrometer compared to the slow water vapor adsorption-desorption processes at the piping and cell walls.

An independent calibration of the humidity generator is still pending, which in particular is necessary to verify full 


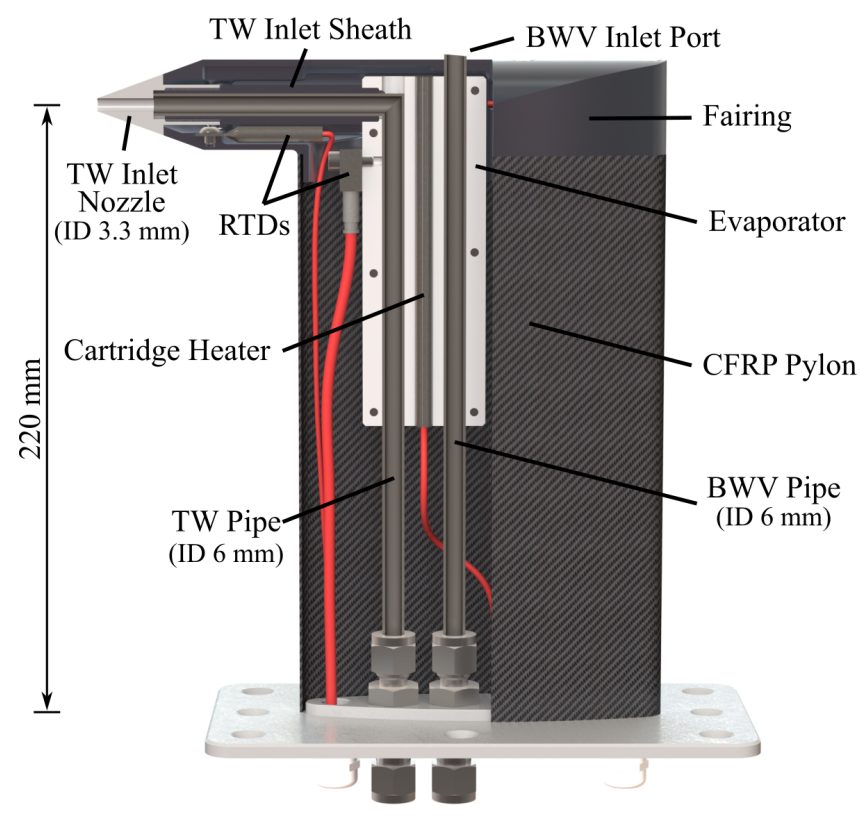

Figure 2. Schematic of the isokinetic evaporator probe assembly showing a partial cut through the main components: TW and BWV inlet lines with TW inlet nozzle, the carbon fiber reinforced polymer (CFRP) pylon, aluminum fairing, and evaporator. Fairing cartridge heaters extending alongside the TW inlet sheath are not indicated.

saturation at high loads (high saturator temperature). To assess the HG and thus hygrometer accuracy, the uncertainty in the generated humidity is calculated from first principles, i.e., the measured saturator temperature and pressure and the associated uncertainties, according to Meyer et al. (2008). The resulting uncertainty $(95 \%)$ is below $\pm 2.1 \%$ over the entire range of humidities provided by the HG and is dominated by the saturator temperature measurement uncertainty (cf. Table E1).

\subsection{Isokinetic evaporator probe}

The inlet system was designed around the three requirements of enabling reasonably representative isokinetic TW sampling while providing the necessary heating power for hydrometeor evaporation and maintaining the probe free from ice accretion at high water content. The probe inlets are housed in an airfoil-shaped $(32 \times 132) \mathrm{mm}$ (width $\times$ length) carbon fiber reinforced polymer (CFRP) pylon capped by an additively manufactured aluminum fairing with the TW centerline extending $220 \mathrm{~mm}$ perpendicular to the free-stream flow from a $(100 \times 195) \mathrm{mm}$ base flange. A CAD drawing of the IKP is shown in Fig. 2.

The fairing is controlled to a TW inlet nozzle temperature of approximately $50^{\circ} \mathrm{C}$ by maintaining a constant $80^{\circ} \mathrm{C}$ at the RTD (Pt100) inside the fairing front tip. To this end, integrated cartridge heaters in the aluminum enclosure provide a maximum combined heating power of $390 \mathrm{~W}$.

\subsubsection{Total water inlet}

TW is sampled through a screw-on aluminum nozzle with a sharp leading edge and a tapering half angle of $20^{\circ}$. For the measurements presented, a nozzle with an inlet inner diameter of 3.30(15) $\mathrm{mm}$, measured with a standard caliper, was used. The particular choice of the comparatively small inlet diameter is based on the maximum continuous flow rate attainable with the low-noise vacuum pump in use, which in combination with the TW inlet area determines the maximum wind tunnel airspeed for which isokinetic sampling may be maintained. The ID of $3.3 \mathrm{~mm}$ corresponds to a maximum airspeed slightly above the main targeted wind tunnel airspeed of $60 \mathrm{~m} \mathrm{~s}^{-1}$. The stated nozzle inner diameter uncertainty is attributed to the measurement method and measurable inlet deformations caused by the machining process.

As the TW inlet is considered a thick-walled inlet with an aspiration efficiency expected to deviate from an ideal sampling behavior (Belyaev and Levin, 1974), the collection efficiency of the inlet was determined from combined computational fluid dynamics (CFD) and Lagrangian particle tracking simulations. Definitions of aspiration and collection efficiency, as well as the particle Stokes number $S t_{\mathrm{p}}$ used in the evaluation, are given in Appendix C. Simulations were carried out in COMSOL Multiphysics software with a workflow similar to the one described by Krämer and Afchine (2004) and showed good agreement with simulations carried out in ANSYS CFX for the same probe with an inlet diameter of $4.6 \mathrm{~mm}$. However, instead of determining the limiting freestream area $A_{\text {lim }}$ comprising all particle trajectories entering the inlet, collection efficiencies $E\left(d_{\mathrm{p}}\right)$ for each droplet diameter $d_{\mathrm{p}}$ considered were calculated from the ratio of the number $N_{\mathrm{S}}$ of droplets sampled to the number $N_{\text {inlet }}$ of droplets passing through the probe TW inlet equivalent area $A_{\text {inlet }}$ in freestream (cf. Appendix C):

$E\left(d_{\mathrm{p}}\right)=\frac{A_{\text {lim }}}{A_{\text {inlet }}} \approx \frac{N_{\mathrm{s}}}{N_{\text {inlet }}}$.

Figure 3 shows the determined collection efficiencies for two IWT freestream airspeeds $U_{\mathrm{a}}$ and different isokinetic factors IKF $=\bar{U}_{\mathrm{s}} / U_{\mathrm{a}}$, i.e., velocity ratios of mean inlet sampling velocity $\bar{U}_{\mathrm{s}}$ to freestream airspeed. Low collection efficiencies at Stokes numbers around 1 are the result of the thick-walled inlet design (Rader and Marple, 1988). At the conditions of the measurements presented herein $\left(U_{\mathrm{a}}=\right.$ $60 \mathrm{~m} \mathrm{~s}^{-1}$ and IKF $\approx 1$ ), the simulated collection efficiency reaches a minimum of $88 \%$ for particles of $3 \mu \mathrm{m}$ diameter and is practically independent of the IKF in the range of 0.95 to 1.05 for diameters above $10 \mu \mathrm{m}\left(S t_{\mathrm{p}} \approx 7\right)$. For $S t_{\mathrm{p}} \ll 1$, the collection efficiency tends towards the value of the isokinetic factor. Consequences of the non-representative sampling on cloud CWC measurement depend on the individual particle size distribution and are discussed in further detail in Sect. 4.3. 


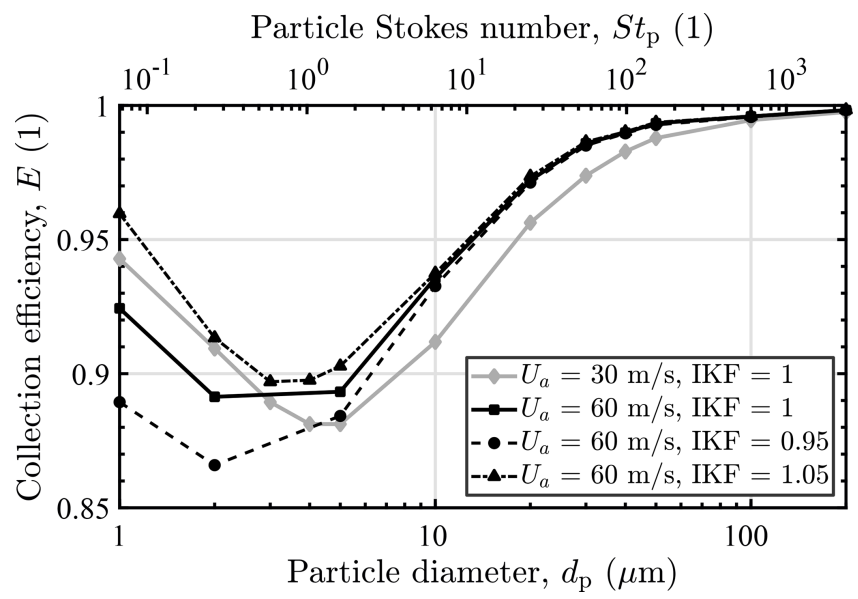

Figure 3. Isoaxial TW inlet collection efficiency as a function of particle diameter determined from combined CFD and Lagrangian particle tracking simulations at different freestream airspeeds $U_{\mathrm{a}}$ and isokinetic factors (IKFs), assuming an ambient air temperature and pressure of $-5^{\circ} \mathrm{C}$ and $1013.25 \mathrm{hPa}$, respectively. Particle Stokes numbers given in the upper $x$ axis are only valid for $60 \mathrm{~m} \mathrm{~s}^{-1}$ data. The lines between the evaluation points are used to guide the eye.

Hydrometeors aspirated through the TW inlet are transported down $6 \mathrm{~mm}$ inner diameter stainless steel tubing to the evaporator, a $(125 \times 44 \times 16) \mathrm{mm}$ aluminum block controlled to $180^{\circ} \mathrm{C}$ by a $400 \mathrm{~W}$ cartridge heater. An aluminum sheath connects the evaporator and the nozzle and ensures additional heat transfer from the evaporator to the inlet. A sharp $90^{\circ}$ bend of the tubing approximately $100 \mathrm{~mm}$ downstream from the inlet forms an impactor, where larger droplets and particles are impacted on the heated wall to increase heat transfer and promote droplet or particle break-up. At the bend, the piping is enclosed and in good thermal contact with the evaporator.

For the airspeed of $60 \mathrm{~m} \mathrm{~s}^{-1}$ and the conditions of the measurements presented, calculated particle stopping distances $S_{\mathrm{p}}$ (cf. Appendix C) predict impaction at the bend for particles with diameters larger than approximately $15 \mu \mathrm{m}$. This is in close agreement with the CFD and Lagrangian particle tracking calculations. The calculated stopping distance in dependence of the particle diameter is shown in Fig. 4 together with the stopping distance equal to the evaporator pipe diameter (dotted line).

Also shown is a theoretical calculation of the evaporative mass loss of supercooled spherical droplets when passing the heated probe pipe section following the $90^{\circ}$ bend. Droplet evaporation was calculated with the two-parameter model (droplet mass and temperature) summarized by Davis et al. (2007), which includes diffusion of water vapor from the droplet to the humid inlet air, associated latent heat losses, and conductive heating of the droplet by the heated inlet air. For the computations, a minimum (centerline) air tempera-

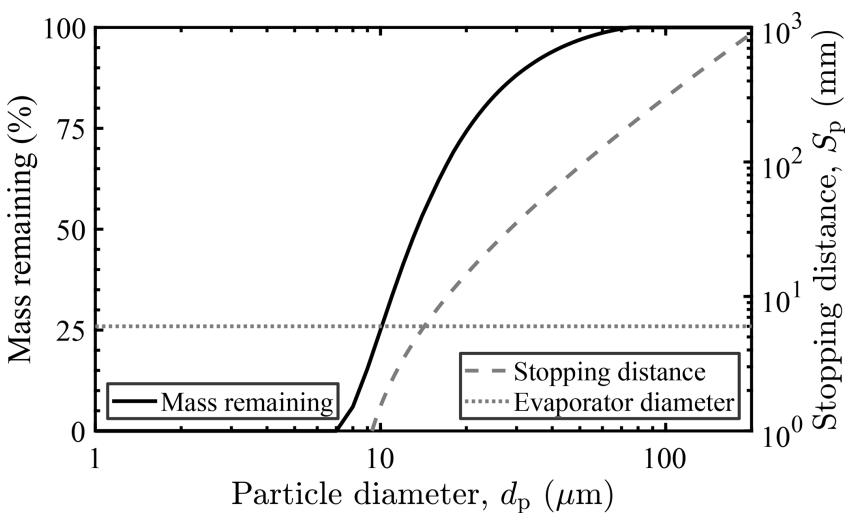

Figure 4. Calculated droplet mass remaining after traversing the probe TW pipe following the evaporator bend and stopping distance as a function of the initial droplet diameter, assuming an ambient air temperature, pressure, and freestream airspeed of $-5^{\circ} \mathrm{C}$, $1013.25 \mathrm{hPa}$, and $60 \mathrm{~m} \mathrm{~s}^{-1}$, respectively. The indicated evaporator diameter marks the stopping distance equal to the inlet pipe diameter of $6 \mathrm{~mm}$.

ture of $50^{\circ} \mathrm{C}$ was assumed, which was determined from the $\mathrm{CFD}$ and heat transfer analysis. Inlet ambient air was assumed to be fully saturated at $-5^{\circ} \mathrm{C}$, with an additional worst case evaporated cloud CWC of $10 \mathrm{~g} \mathrm{~m}^{-3}$.

Droplets with diameters above $15 \mu \mathrm{m}$ impact the $180^{\circ} \mathrm{C}$ evaporator walls and are assumed to evaporate due to the increased heat transfer or break up into smaller, more easily evaporated droplets. Minimum residence times of $1 \mathrm{~s}$ in the attached $7 \mathrm{~m}$ long tubes heated to $35^{\circ} \mathrm{C}$ are considered sufficient to achieve full evaporation of smaller droplets. However, observable TW signal oscillations for inlet condensed water mass flow rates above $0.8 \mathrm{mg} \mathrm{s}^{-1}$ (hydrometeor mass flux of approx. $90 \mathrm{~g} \mathrm{~m}^{-2} \mathrm{~s}^{-1}$ ) suggest temporary accumulation of water or ice in the small diameter nozzle or at the evaporator and are the reason for further investigation into the process of droplet and particle evaporation for the chosen inlet diameter and evaporator geometry.

\subsubsection{Background water vapor inlet}

The BWV inlet port is used for sampling ambient air with the PA cell mass flow rate of $0.75 \mathrm{slpm}$ and may be extended by a rearward-facing probe with a $16 \mathrm{~mm}$ ID connected to $4 \mathrm{~mm}$ ID tubing. The connection between the rearwardfacing probe and the port was thermally insulated to reduce heating of the inlet, as the port pipe is in direct contact with the evaporator. For the measurements presented, only a single hygrometer used for TW measurement was available, thus the IKP was used without the rearward-facing probe and BWV was estimated from IWT humidity sensors. The method of BWV estimation is described in further detail in Sect. 5. 


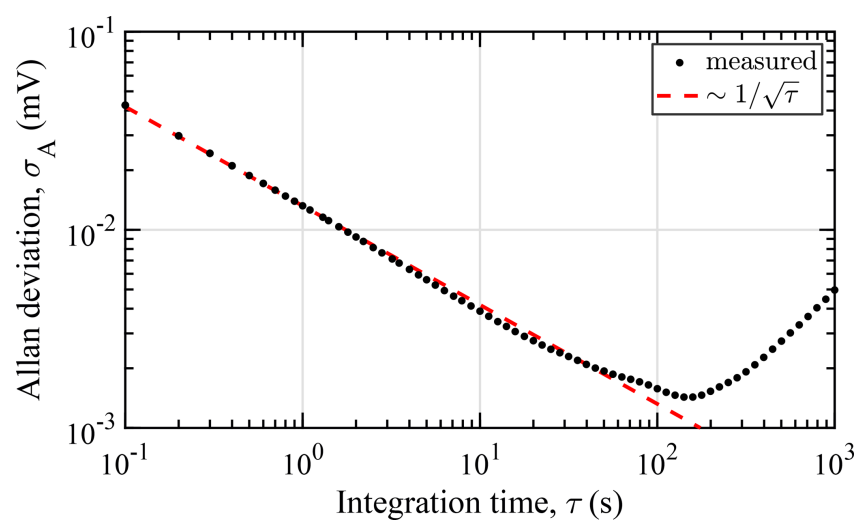

Figure 5. Allan deviation $\sigma_{\mathrm{A}}$ calculated from the measured signal amplitude of a $1 \mathrm{~h}$ background measurement with zero air as a function of the lock-in integration time $\tau$. The dotted line indicates a $1 / \sqrt{\tau}$ decrease in noise, typical for white noise averaging.

\section{Hygrometer characterization and calibration}

\subsection{Noise, limit of detection, and response time}

To quantify measurement noise, expectable system drift, and the limit of detection (LOD) of the hygrometer, an Allan deviation analysis (Werle et al., 1993) was performed on a background measurement with zero air acquired at $10 \mathrm{~Hz}$ with an integration time of $0.1 \mathrm{~s}$. Figure 5 shows the Allan deviation $\sigma_{\mathrm{A}}$, i.e., an estimate for the standard deviation of the mean of the background signal, as it depends on the averaging or integration time $\tau$.

The system exhibits a $1 / \sqrt{\tau}$ decrease in noise, typical for white noise averaging, up to a maximum useful averaging time of $150 \mathrm{~s}$, where drift starts to deteriorate system performance. The effectiveness of increasing integration time is limited by a slow drift of the measurement gas temperature. For half the maximum useful averaging time, an LOD $\left(3 \sigma_{\mathrm{A}}\right)$ calculated from the calibration curve (see Sect. 3.2) of $3.2 \mathrm{ppm}$ water vapor mole fraction or $2.0 \mathrm{mg} \mathrm{kg}^{-1}$ in terms of humid air mass mixing ratio at standard temperature and pressure (STP; $273.15 \mathrm{~K}$ and $1000 \mathrm{hPa}$ ) can be achieved. More practical averaging times of 1 and $10 \mathrm{~s}$ result in $3 \sigma_{\mathrm{A}}$ noise equivalent concentrations of 23 and $7 \mathrm{ppm}$, respectively. A comparison to literature-reported detection limits of photoacoustic hygrometers is given in the Supplement to this work. The implementation of a wavelength modulation scheme of the laser diode is expected to result in a reduction of the background signal noise and a significant improvement of the achievable LOD.

As the $1 \mathrm{~s}$ averaging time precision - equivalent to $14 \mathrm{mg} \mathrm{kg}^{-1}$ mass mixing ratio at STP - is sufficient for IWT water content measurement and results in a favorable response time, this lock-in integration time is applied in calibration and water content measurements. With a $1 \mathrm{~s}$ averaging time, response and recovery times $(63.2 \% \mathrm{PA}$ sig- nal change) of $\tau_{63}=1.7(2) \mathrm{s}$ and $\tau_{63}=2.2(2) \mathrm{s}$, respectively, have been determined by alternately sampling humidified zero air and ambient air. Response and recovery times for $90 \%$ signal change are about four times the stated values of $\tau_{63}$. An example response time measurement is shown in Fig. D1 in Appendix D. It is noted that response and recovery times of the described setup are assumed to be longer for measurements of background or total water concentrations below $500 \mathrm{ppm}$ (dew points below $-30^{\circ} \mathrm{C}$ ) due to adsorption-desorption effects associated with the polar nature of water and the long PTFE tubing connecting the probe and the measurement unit (Wiederhold, 1997).

\subsection{Hygrometer calibration}

The hygrometer is calibrated at constant PA cell temperature and pressure $\left(800 \mathrm{hPa}, 35^{\circ} \mathrm{C}\right)$ with the built-in two-pressure HG. To quantify measurement uncertainties at dew points lower than provided by the HG, a gas diluter (Breitegger and Bergmann, 2018) was used for an initial laboratory calibration. Using the gas diluter, humidified air provided by the humidity generator was further diluted with zero air, down to a minimum water vapor mole fraction of $124 \mathrm{ppm}$. Background corrected calibration data recorded at concentrations in the range of 124 to $22150 \mathrm{ppm}$ and the inverse calibration curve used to determine the water vapor mole fraction during water content measurement are shown in Fig. 6. Signal amplitude noise of the hygrometer during calibration is typically below water vapor mole fractions of $10 \mathrm{ppm}$ or $0.7 \%$ (the higher value in absolute terms applies). The former value, applicable at low concentrations, is on the order of the background signal noise $(1 \sigma)$ determined by the Allan deviation analysis for the integration time of $1 \mathrm{~s}$.

For the determination of the water vapor mole fraction during water content measurement, the calibration data are approximated by the inverse of the theoretically motivated nonlinear five-parameter calibration function given by Lang et al. (2020), which accounts for the humidity-dependent hygrometer sensitivity. As opposed to higher-order polynomials, which are necessary to reproduce the nonlinear functional relationship, this calibration function adds the benefit of a well-defined behavior for inter- and extrapolation when faced with a reduced number of calibration points. The parameters $\boldsymbol{b}$ of the calibration curve are determined with the weighted nonlinear least-squares method, minimizing

$\chi^{2}=\sum_{i=1}^{N} w_{x, i}\left[x_{\mathrm{w}, i}-f^{-1}\left(S_{i}, \boldsymbol{b}\right)\right]^{2}$

over the $N$ calibration measurements, where $f^{-1}\left(S_{i}, \boldsymbol{b}\right)$ is the inverse calibration function evaluated at the measured PA signal amplitude $S_{i}$ and for the parameter set $\boldsymbol{b}$. The inverse of the calibration function was used in order to include the uncertainty of the calibration water vapor mole fraction $u\left(x_{\mathrm{w}, i}\right)$ in the determination of the parameters and parame- 


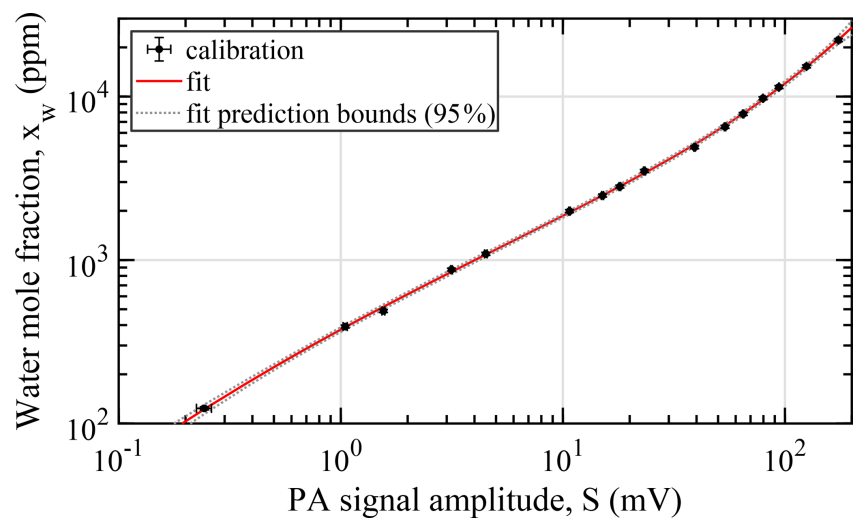

Figure 6. Laboratory calibration data of the PA hygrometer operated at $35^{\circ} \mathrm{C}, 800 \mathrm{hPa}$, and an integration time of $1 \mathrm{~s}$. Calibration humidities were set with the internal humidity generator and in combination with the gas diluter. The fit indicates the best-fit calibration curve with the parameters obtained by the weighted nonlinear least-squares method. Error bars of the measurements indicate the $95 \%$ uncertainty of the humidity generation and standard deviation of the lock-in signal for the $y$ and $x$ axes, respectively.

ter confidence intervals. To this end, each calibration point $i$ is weighted by $w_{x, i}=1 / \sigma_{x, i}^{2}=1 / u^{2}\left(x_{\mathrm{w}, i}\right)$, i.e., according to the combined uncertainty in the humidity provided by the humidity generator and gas diluter. The uncertainty in the mean of the measured PA signal amplitude is negligible in comparison to the uncertainty in the mole fraction and therefore is disregarded in the least-squares fit. Residuals, i.e., the differences between calibration data and calibration curve, are typically below $3 \%$. This remaining variability is largely explained by the error in the generated humidity and changes in microphone sensitivity from temperature oscillations of the PA cell.

\subsection{Estimation of hygrometer measurement uncertainty}

The measurement uncertainty of the PA hygrometer is the result of uncertainties originating from the calibration and from noise during measurement. Calibration uncertainty itself includes uncertainties from humidity generation and from the approximation by the calibration function. These uncertainties have been jointly estimated from the parameter uncertainties obtained with the nonlinear least-squares method. Instrument signal noise $(1 \sigma)$ is taken to be equivalent to the calibration noise (10 ppm or $0.7 \%$, whichever is higher). Details of the determination of the combined hygrometer uncertainty are given in Appendix F of this work.

The calculated relative measurement uncertainty of the hygrometer (95\% coverage) as a function of the measured water vapor mole fraction is shown in Fig. 7. Measurement uncertainty can be seen to increase rapidly for mole fractions below $200 \mathrm{ppm}$ and above $23000 \mathrm{ppm}$, due to the lack of calibration points at lower and higher water vapor concentra- tions. Nevertheless, in the range of expected condensed water content and background humidities encountered during typical IWT evaluation, the hygrometer exhibits an accuracy better than $2.5 \%$ to $3.3 \%$. This target water content range is defined by the lower limit of cloud-free, but fully saturated, air (with respect to supercooled liquid) at $-30^{\circ} \mathrm{C}$ and the upper limit of $5 \mathrm{~g} \mathrm{~m}^{-3}$ in fully saturated air at $0^{\circ} \mathrm{C}$. These limits correspond to 512 and $12361 \mathrm{ppm}$ at standard pressure, respectively. Fully saturated air is assumed, as high relative humidity is typical during measurement in closed-circuit icing wind tunnels. Increasing lock-in integration time can be seen to not yield notable performance improvement, as accuracy in the range of interest is dominated by the uncertainty in the calibration humidity.

The determined PA hygrometer accuracy is lower than the accuracy specified for NDIR systems providing a similar measurement range (e.g., 1.5\%; LI-COR Inc., 2020). However, because the accuracy of the hygrometer is currently dominated by the accuracy of the humidity generator, it is expected that improvement of saturator temperature stability and temperature measurement, combined with the independent calibration of the HG, will further improve the accuracy of the hygrometer to similar levels.

\subsection{Measurement stability and repeatability}

The short-term stability of the hygrometer during measurement, which is essential to the instrument accuracy in between calibrations, was evaluated by supplying a steady flow of humidified air to the PA cell using the instrument calibration unit. The stability measured over a period of three hours is shown in Fig. 8a, which shows the relative deviation of the estimated water vapor mole fraction from a $1 \mathrm{~s}$ running average of the mole fraction supplied by the instrument's humidity generator over time. Estimated concentrations remained within $\pm 1.8 \%$ of the reference concentration and are well within the $\pm 2.4 \%$ relative uncertainty of the humidity generator ( $95 \%$ coverage). The determined stability is also within the $3.3 \%$ accuracy of the hygrometer. Negative peaks in Fig. $8 \mathrm{a}$ at $0.4,0.8$, and $1.2 \mathrm{~h}$ are the result of decreased microphone sensitivity due to minor temperature rises of the PA cell, and the observable oscillation with a period of approximately $3 \mathrm{~h}$ correlates strongly with the drift-corrected temperature inside the instrument rack. Stabilizing the rack temperature is, thus, expected to further improve the instrument stability and accuracy.

The hygrometer is calibrated on a daily basis because for longer intervals drift in the lower percentage range has been observed in between calibrations. This drift is mainly associated with a drift in the laser power and the non-existent laser power correction of the PA signal (cf. Sect. 2.1). Therefore, measurement repeatability was assessed only by an analysis of the stability over intervals of 2 consecutive days, where no drift greater than $2 \%$ was observed (cf. Fig. $8 b$ ). 


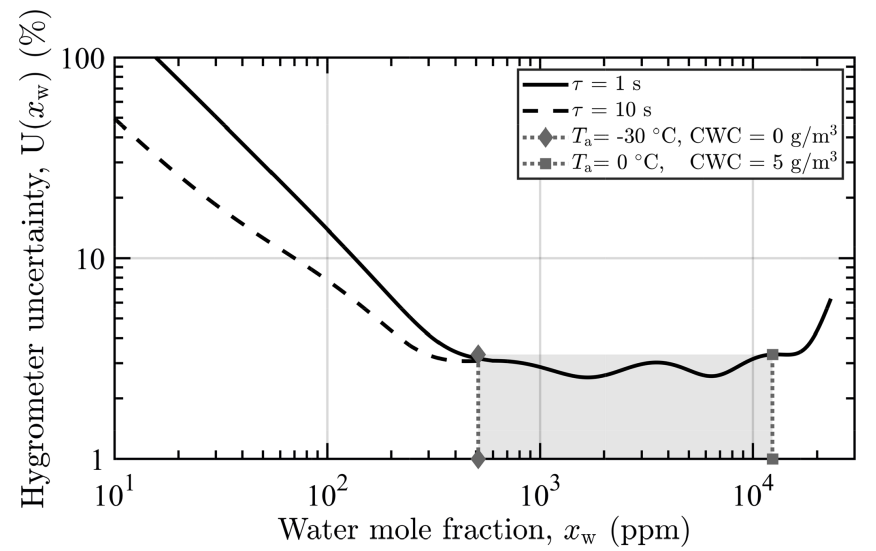

Figure 7. Relative measurement uncertainty ( $95 \%$ coverage) of the photoacoustic hygrometer operated at $35^{\circ} \mathrm{C}, 800 \mathrm{hPa}$, and with integration times $\tau$ of 1 and $10 \mathrm{~s}$. The gray area bounded by dotted vertical lines marks the target range of background and total water content, defined by the lower limit CWC of $0 \mathrm{~g} \mathrm{~m}^{-3}$ at $-30^{\circ} \mathrm{C}(512 \mathrm{ppm})$ and the upper limit of $5 \mathrm{~g} \mathrm{~m}^{-3}$ at $0^{\circ} \mathrm{C}(12361 \mathrm{ppm})$. The air is assumed to be fully saturated with respect to supercooled liquid.

(a)

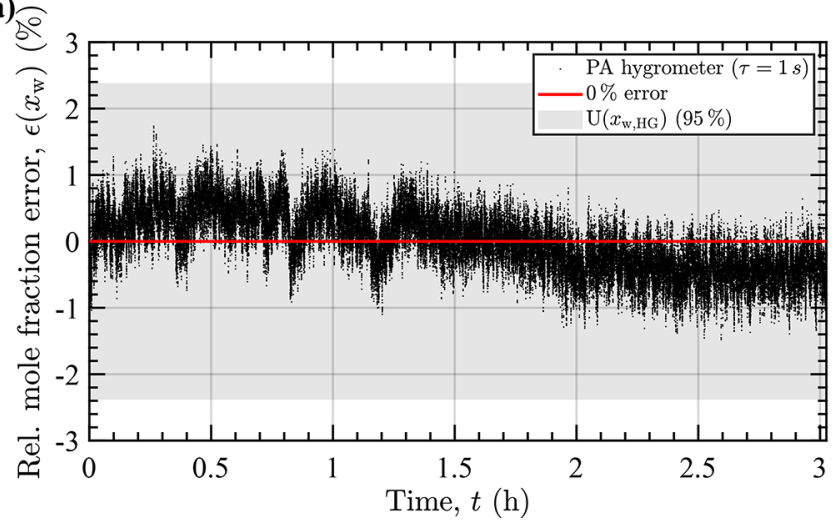

(b)

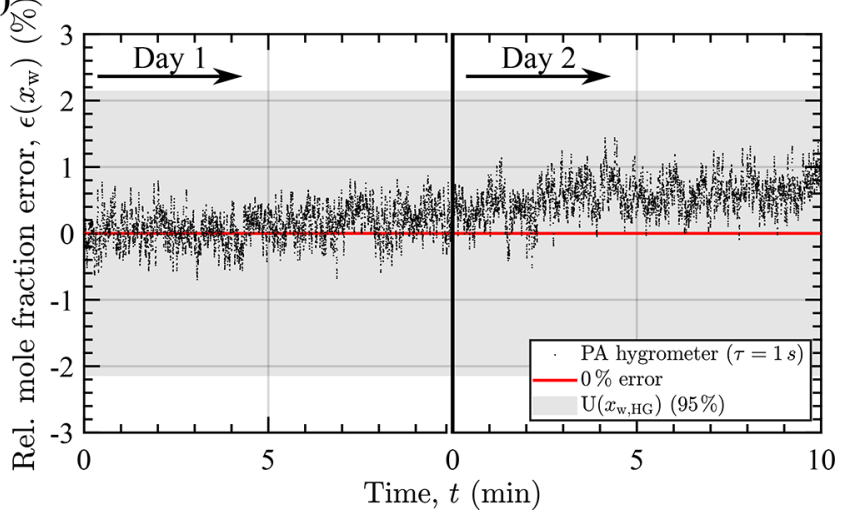

Figure 8. Hygrometer measurement stability. (a) Relative deviation of the measured water vapor mole fraction from the reference concentration of $9620(80)$ ppm supplied by the calibration unit over time. (b) Relative deviation on two consecutive days, measured at a mole fraction of 18800(160) ppm and calculated using the calibration of day 1 in both measurements. The gray bands mark the relative uncertainty of the water vapor mole fraction provided by the humidity generator $(\mathbf{a} \pm 2.4 \%, \mathbf{b} \pm 2.2 \%$, both $95 \%$ coverage). The lock-in integration time used for all measurements was $1 \mathrm{~s}$.

\section{CWC measurement and uncertainty}

Derivation of the cloud condensed water content from the measured TW mole fraction $x_{\mathrm{w}, \text { tot }}$ and the ambient air BWV mole fraction $x_{\mathrm{w}, \mathrm{a}}$ requires additional input from the instrument's flow measurement, together with input about the icing wind tunnel operating conditions. Equations used to derive the actual condensed water content and the corresponding measurement uncertainty from the measured quantities are briefly described in the following subsections.

Measurement of the CWC, defined as the mass of condensed water in the form of hydrometeors per volume of air, is accompanied by hydrometeor and air sampling errors introduced by deviations from the ideal and isokinetic sampling at the TW inlet. These errors are corrected by accounting for the actual mass averaged hydrometeor aspiration ef- ficiency of the probe for the given particle size distribution $\bar{\eta}_{\text {asp }}$ (cf. Appendix C; Belyaev and Levin, 1974):

$$
\mathrm{CWC}_{\mathrm{i}}=\bar{\eta}_{\text {asp }} \mathrm{CWC}=\frac{\bar{E}}{\mathrm{IKF}} \mathrm{CWC} .
$$

Here, $\mathrm{CWC}_{\mathrm{i}}$ is the indicated or measured condensed water content and $\bar{E}$ is the mass averaged hydrometeor collection efficiency of the probe.

Under ideal and isokinetic sampling conditions, the CWC is equal to the ratio of the mass flow rate of hydrometeors to the volumetric flow rate of air entering the probe TW inlet. At the inlet, the volume of air occupied and displaced by the liquid or solid hydrometeors can be assumed to be negligible for the water content of interest (Davison et al., 2016). Indicated condensed water content $\mathrm{CWC}_{\mathrm{i}}$ is the ratio of the actually sampled hydrometeor mass flow rate $\dot{m}_{\mathrm{h}}$ to the sam- 
pled volumetric flow rate of air $q_{\mathrm{a}}$. Thus, using Eq. (3), CWC may be calculated from the expression

$\mathrm{CWC}=\mathrm{CWC}_{\mathrm{i}} \frac{\mathrm{IKF}}{\bar{E}}=\frac{\dot{m}_{\mathrm{h}}}{q_{\mathrm{a}}} \cdot \frac{\mathrm{IKF}}{\bar{E}}$.

\subsection{Indicated CWC}

The flow rates $\dot{m}_{\mathrm{h}}$ and $q_{\mathrm{a}}$ may be expressed in terms of the total mass flow sampled through the TW inlet $\dot{m}_{\text {tot }}$ (IWT air, including hydrometeors), the mass flow of humid ambient air $\dot{m}_{\mathrm{a}}$ (IWT air, excluding hydrometeors), and the ambient air density $\rho_{\mathrm{a}}$. The indicated CWC is then calculated from

$$
\begin{aligned}
\mathrm{CWC}_{\mathrm{i}} & =\frac{\dot{m}_{\mathrm{h}}}{q_{\mathrm{a}}}=\frac{\dot{m}_{\mathrm{tot}}-\dot{m}_{\mathrm{a}}}{\dot{m}_{\mathrm{a}} / \rho_{\mathrm{a}}} \\
& =\rho_{\mathrm{a}}\left(\frac{\omega_{\mathrm{da}, \mathrm{a}}}{\omega_{\mathrm{da}, \text { tot }}}-1\right) \\
& =\frac{p_{\mathrm{a}} M_{\mathrm{w}}}{R T_{\mathrm{a}}} \cdot \frac{x_{\mathrm{w}, \text { tot }}-x_{\mathrm{w}, \mathrm{a}}}{1-x_{\mathrm{w}, \text { tot }}},
\end{aligned}
$$

where the density of the air was calculated assuming an ideal gas mixture of dry air (subscript da) and water vapor:

$$
\begin{aligned}
\rho_{\mathrm{a}} & =\rho_{\mathrm{da}}+\rho_{\mathrm{w}, \mathrm{a}} \\
& =\frac{p_{\mathrm{a}}}{R T_{\mathrm{a}}}\left[M_{\mathrm{da}}\left(1-x_{\mathrm{w}, \mathrm{a}}\right)+M_{\mathrm{w}} x_{\mathrm{w}, \mathrm{a}}\right] .
\end{aligned}
$$

$\omega_{\mathrm{da}, \text { tot }}$ and $\omega_{\mathrm{da}, \mathrm{a}}$ are the dry air mass fractions of the sampled TW air, which includes evaporated hydrometeors, and of the ambient air, respectively:

$$
\begin{aligned}
& \omega_{\mathrm{da}, \mathrm{tot}}=\frac{\dot{m}_{\mathrm{da}}}{\dot{m}_{\mathrm{tot}}}=\frac{M_{\mathrm{da}}\left(1-x_{\mathrm{w}, \mathrm{tot}}\right)}{M_{\mathrm{da}}\left(1-x_{\mathrm{w}, \mathrm{tot}}\right)+M_{\mathrm{w}} x_{\mathrm{w}, \mathrm{tot}}}, \\
& \omega_{\mathrm{da}, \mathrm{a}}=\frac{\dot{m}_{\mathrm{da}}}{\dot{m}_{\mathrm{a}}}=\frac{M_{\mathrm{da}}\left(1-x_{\mathrm{w}, \mathrm{a}}\right)}{M_{\mathrm{da}}\left(1-x_{\mathrm{w}, \mathrm{a}}\right)+M_{\mathrm{w}} x_{\mathrm{w}, \mathrm{a}}} .
\end{aligned}
$$

$T_{\mathrm{a}}$ and $p_{\mathrm{a}}$ are the icing wind tunnel static air temperature and pressure. $M_{\mathrm{da}}$ and $M_{\mathrm{w}}$ are the molar masses of dry air and water and $R$ is the universal gas constant. Real gas effects at the measurement temperatures, pressures, and humidities of interest are minor.

\subsection{Isokinetic factor and collection efficiency}

The TW inlet flow rate is only set to isokinetic sampling once before activation of the IWT spray system. As the inlet total mass flow rate is held constant and is measured downstream the evaporator, water vapor originating from hydrometeor evaporation reduces the inlet air flow rate during TW measurement, altering the flow field at the probe inlet and reducing the IKF. In addition to this reduction of the IKF, minor changes in the IWT air density $\rho_{\mathrm{a}}$ or airspeed $U_{\mathrm{a}}$ during measurement also lead to deviations from the initially set isokineticity.

The isokinetic factor in Eq. (4) corrects for these sources of disproportional sampling of ambient air in comparison to isokinetic sampling and is determined during measurement from

$\mathrm{IKF}=\frac{\bar{U}_{\mathrm{s}}}{U_{\mathrm{a}}}=\frac{\dot{m}_{\mathrm{a}}}{U_{\mathrm{a}} \rho_{\mathrm{a}} A_{\text {inlet }}}=\frac{4 \dot{m}_{\mathrm{a}}}{U_{\mathrm{a}} \rho_{\mathrm{a}} d_{\text {inlet }}^{2} \pi}$,

where $d_{\text {inlet }}$ is the diameter of the circular probe TW inlet.

Since, with a decrease of the IKF, the collection efficiency at high particle Stokes numbers decreases sub-proportionally to the efficiency at lower Stokes numbers (cf. Fig. 3), condensed water content is overestimated for typical particle size distributions. For each specific particle size distribution encountered during measurement, the mass averaged collection efficiency $\bar{E}$ in Eq. (4) may be used to correct for the size and IKF-dependent sampling efficiency.

\subsubsection{Mass flow measurement}

The ambient air mass flow rate $\dot{m}_{\mathrm{a}}$ required for the calculation of the IKF is determined from the total mass flow sampled through the TW inlet, i.e., the combined mass flow rates through the PA cell $\dot{m}_{\text {cell }}$ and the bypass path $\dot{m}_{\text {bp }}$. Together with Eqs. (10)-(11), the ambient air mass flow rate (excluding hydrometeors) through the TW inlet is given by

$\dot{m}_{\mathrm{a}}=\frac{\omega_{\mathrm{da}, \mathrm{tot}}}{\omega_{\mathrm{da}, \mathrm{a}}} \dot{m}_{\mathrm{tot}}=\frac{\omega_{\mathrm{da}, \text { tot }}}{\omega_{\mathrm{da}, \mathrm{a}}}\left(\dot{m}_{\mathrm{cell}}+\dot{m}_{\mathrm{bp}}\right)$.

The thermal mass flowmeters are calibrated for dry air assuming dry air specific heat capacity for the gas to be measured. As humid air isobaric heat capacity increases by $1 \%$ at the maximum expected TWC $\left(10 \mathrm{~g} \mathrm{~m}^{-3} \mathrm{CWC}\right.$, fully saturated air at STP), the indicated volumetric standard flow rates of the flowmeters, $q_{\mathrm{cell}, 0}$ and $q_{\mathrm{bp}, 0}$, are converted to humid air mass flow rates (Hardy et al., 1999):

$$
\begin{aligned}
\dot{m}_{j} & =\frac{c_{\mathrm{p}, \mathrm{da}}}{c_{\mathrm{p}, \mathrm{tot}}} \rho_{\mathrm{da}, 0} q_{j, 0} \\
& =\frac{c_{\mathrm{p}, \mathrm{da}}}{c_{\mathrm{p}, \mathrm{da}} \omega_{\mathrm{da}, \mathrm{tot}}+c_{\mathrm{p}, \mathrm{w}}\left(1-\omega_{\mathrm{da}, \mathrm{tot}}\right)} \rho_{\mathrm{da}, 0} q_{j, 0},
\end{aligned}
$$

where $j=\{$ cell, bp $\}$ refers to the cell or bypass measurement, $\rho_{\mathrm{da}, 0}$ is the dry air density at standard temperature and $1013.25 \mathrm{hPa}, c_{\mathrm{p}, \mathrm{da}}$ is the isobaric specific heat capacity of dry air, and the specific heat capacity of humid air $c_{\mathrm{p} \text {,tot is calcu- }}$ lated assuming an ideal mixture model. The remaining mass flow error after applying the above heat capacity correction has not yet been determined. However, the error is assumed to be below $1 \%$, as the change in air specific heat capacity itself is below $1 \%$ at the maximum expected total water content.

\subsubsection{CWC estimation}

The final expression used for icing wind tunnel CWC estimation is obtained by combining Eq. (4) with Eqs. (7) and (10)- 
(14):

$$
\begin{aligned}
\mathrm{CWC} & =\frac{4 M_{\mathrm{w}}}{\pi d_{\text {inlet }}^{2} U_{\mathrm{a}} \bar{E}} \\
& \cdot \frac{\rho_{\mathrm{da}, 0} c_{\mathrm{p}, \mathrm{da}}\left(q_{\mathrm{bp}, 0}+q_{\mathrm{cell}, 0}\right)}{c_{\mathrm{p}, \mathrm{da}} M_{\mathrm{da}}\left(1-x_{\mathrm{w}, \mathrm{tot}}\right)+c_{\mathrm{p}, \mathrm{w}} M_{\mathrm{w}} x_{\mathrm{w}, \mathrm{tot}}} \\
& \cdot \frac{x_{\mathrm{w}, \mathrm{tot}}-x_{\mathrm{w}, \mathrm{a}}}{1-x_{\mathrm{w}, \mathrm{a}}} .
\end{aligned}
$$

Although IWT static air temperature and pressure are required to set the total sampling mass flow to isokinetic TW sampling, this result shows that if the isokinetic factor is not calculated explicitly, air temperature and pressure only appear in the hydrometeor collection efficiency (through air viscosity and slip correction) and otherwise are not required to calculate the condensed water content. For minor temperature and pressure fluctuations during IWT water content measurement, only marginal impact on CWC measurement and uncertainty is anticipated by disregarding changes in IWT air temperature and pressure.

\subsection{CWC measurement uncertainty}

Corrections and errors introduced by the collection efficiency are specific to the respective wind tunnel icing conditions and hence are not considered in the following general analysis. Instead, a mean mass averaged collection efficiency of 1 is assumed. With the numerically determined collection efficiency given in Fig. 3, maintaining this assumption for the evaluation of the presented measurements in icing conditions of freezing drizzle or rain, with median volume diameters (MVDs) in the range of $100 \mu \mathrm{m}$ to $650 \mu \mathrm{m}$, the potential CWC underestimation is below $1 \%$ (size distribution data taken from Cober et al., 2009).

The uncertainty of the condensed water content measurement is derived from a first-order propagation of the uncertainties of the quantities appearing in Eq. (15) according to the Guide to the Expression of Uncertainty in Measurement (GUM; Joint Committee for Guides in Metrology, 2008a). Uncertainties not distributed normally have been converted to standard uncertainties for the analytical calculations. Unless otherwise stated, all uncertainties are given in terms of the $95 \%$ coverage interval. A summary of the individual uncertainties of the input quantities is given in Table E1 in Appendix $E$ of this work.

The current single-hygrometer instrument only allows either TW or BWV content measurement. Alternating between both measurements to determine the CWC inevitably results in a measurement error due to the dynamic behavior of the background water content, which is mainly defined by the initial IWT air saturation level and stability of the temperature conditioning during the measurement. Depending on the saturation level preceding activation of the spray, the background water content during the probe intercomparison increased by up to $0.5 \mathrm{~g} \mathrm{~m}^{-3}$ for as long as five minutes af-

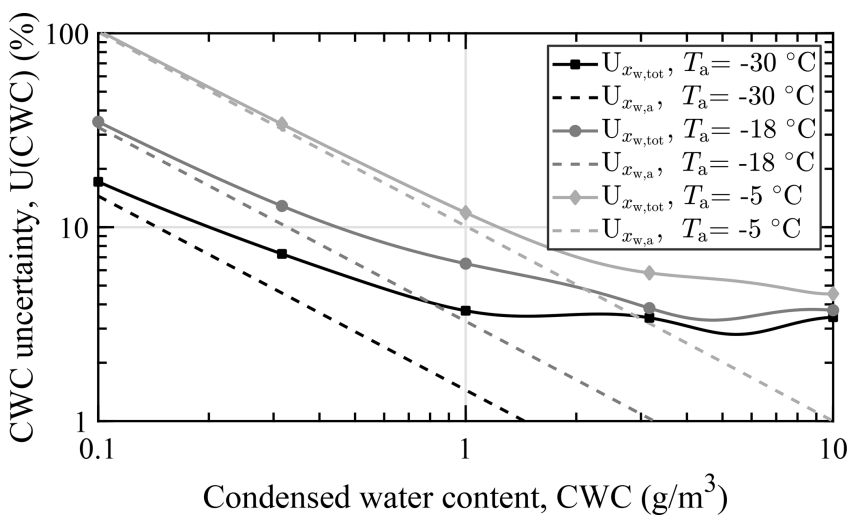

Figure 9. Hygrometer measurement uncertainty contributions to the $95 \%$ CWC measurement uncertainty at three static air temperatures, an airspeed of $60 \mathrm{~ms}^{-1}$, and a static air pressure of $1013.25 \mathrm{hPa}$. Condensed water content uncertainty contributions are given relative to the actual CWC and for isokinetic sampling. The ambient air is assumed to be fully saturated with respect to supercooled liquid.

ter activation of the spray and before reaching a stable reading. As a consequence of alternating TW and BWV measurement, errors highly depend on subjective assessment during evaluation and are specific to the IWT operating conditions. With the goal of assessing instrument accuracy with a planned second dedicated PA cell for background humidity measurement, the uncertainties of the TW and BWV content measurement are both taken to be equal to the hygrometer measurement uncertainty given in Sect. 3.3. The presented uncertainties may, however, be taken as upper limits for a different hygrometer used for background humidity measurement with similar or better accuracy.

Figure 9 shows the calculated hygrometer contribution to the condensed water content measurement uncertainty at three IWT static air temperatures. Temperatures of -30 , -18 , and $-5^{\circ} \mathrm{C}$ were examined, again assuming fully saturated air with respect to supercooled liquid water, as this is expected for the closed-circuit icing wind tunnel. The measurement uncertainty contributions are given relative to the actual CWC. The contributions to the measurement of the background water vapor concentration $\left(\mathrm{U}_{x_{\mathrm{w}, \mathrm{a}}}\right.$; dashed lines) indicate constant background humidities with associated constant absolute measurement uncertainties.

The hygrometer's contribution to the CWC measurement uncertainty increases rapidly with lower water content and increasing temperature. The latter circumstance is a result of the rising absolute BWV concentration uncertainty with increasing background humidity, which dominates the difference of measured total and background water vapor concentrations at low CWC (last term in Eq. 15). For a condensed water content of $0.5 \mathrm{~g} \mathrm{~m}^{-3}$ and an IWT temperature of $-5^{\circ} \mathrm{C}$, the combined hygrometer uncertainty contribution 
(a)

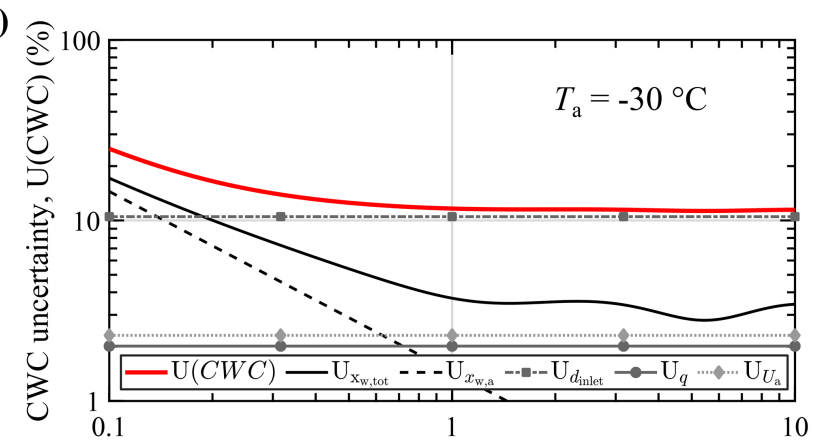

(b)

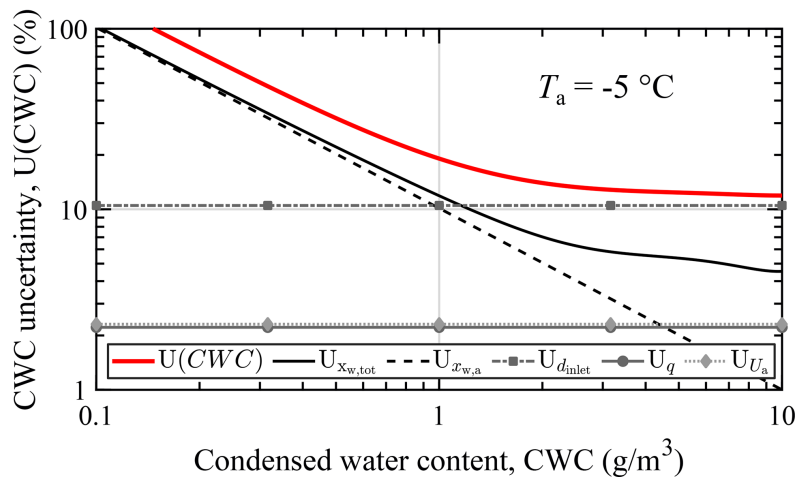

Figure 10. Condensed water content measurement uncertainty $(95 \%)$ and individual contributions at static air temperatures of (a) $-30^{\circ} \mathrm{C}$ and (b) $-5^{\circ} \mathrm{C}$. Uncertainties are given relative to the actual $\mathrm{CWC}$ and for isokinetic sampling. Wind speed and static air pressure are $60 \mathrm{~m} \mathrm{~s}^{-1}$ and $1013.25 \mathrm{hPa}$, respectively. The ambient air is assumed to be fully saturated with respect to supercooled liquid.

(root of sum of squares) is $0.15 \mathrm{~g} \mathrm{~m}^{-3}$. At $-30^{\circ} \mathrm{C}$ the hygrometer's contribution is reduced to $0.03 \mathrm{~g} \mathrm{~m}^{-3}$.

Figure 10 shows the overall CWC measurement uncertainty at two of the above temperatures. Also shown are the individual contributions of the input quantities. At high condensed water content, the device is currently obviously limited by the large relative uncertainty in the probe TW inlet area $( \pm 9 \%)$, which contributes a constant $10.5 \%$ to the overall uncertainty. This is a result of the particularly small size of the TW inlet diameter. However, deviation of the estimated nozzle inlet area from the true size only results in an invariant systematic error in the isokinetic factor. Hence the CWC measurement error should be proportional to the indicated CWC and should not affect instrument precision. The additional error in the projected probe TW inlet area due to misalignment to the direction of flow is below $0.5 \%$, assuming an angle of attack within $\pm 5^{\circ}$. This does not include errors induced by changes in collection efficiency, which again have to be considered separately for the respective particle size distribution.

Towards lower condensed water content, the overall measurement uncertainty is dominated by the humidity measurement. As is typical for IKPs, the accuracy of the instrument
Table 1. Instrument absolute and relative CWC measurement uncertainties (95\% coverage) at selected cloud CWC and at static air temperatures of -5 and $-30^{\circ} \mathrm{C}$. Wind tunnel airspeed and static air pressure for the calculations are $60 \mathrm{~m} \mathrm{~s}^{-1}$ and $1013.25 \mathrm{hPa}$, respectively.

\begin{tabular}{cccc}
\hline$T_{\mathrm{a}}$ & $\mathrm{CWC}$ & \multicolumn{2}{c}{$\mathrm{U}(\mathrm{CWC})$} \\
\hline & $0.25 \mathrm{~g} \mathrm{~m}^{-3}$ & $0.15 \mathrm{~g} \mathrm{~m}^{-3}$ & $60 \%$ \\
$-5{ }^{\circ} \mathrm{C}$ & $0.50 \mathrm{~g} \mathrm{~m}^{-3}$ & $0.16 \mathrm{~g} \mathrm{~m}^{-3}$ & $31 \%$ \\
& $1.00 \mathrm{~g} \mathrm{~m}^{-3}$ & $0.19 \mathrm{~g} \mathrm{~m}^{-3}$ & $19 \%$ \\
& $3.00 \mathrm{~g} \mathrm{~m}^{-3}$ & $0.39 \mathrm{~g} \mathrm{~m}^{-3}$ & $13 \%$ \\
\hline & $0.25 \mathrm{~g} \mathrm{~m}^{-3}$ & $0.04 \mathrm{~g} \mathrm{~m}^{-3}$ & $15 \%$ \\
$-30^{\circ} \mathrm{C}$ & $0.50 \mathrm{~g} \mathrm{~m}^{-3}$ & $0.06 \mathrm{~g} \mathrm{~m}^{-3}$ & $13 \%$ \\
& $1.00 \mathrm{~g} \mathrm{~m}^{-3}$ & $0.12 \mathrm{~g} \mathrm{~m}^{-3}$ & $12 \%$ \\
& $3.00 \mathrm{~g} \mathrm{~m}^{-3}$ & $0.34 \mathrm{~g} \mathrm{~m}^{-3}$ & $11 \%$ \\
\hline
\end{tabular}

is highest at low ambient temperatures or background humidities (Davison et al., 2016). Table 1 summarizes absolute and relative measurement uncertainties $\mathrm{U}(\mathrm{CWC})$ at static air temperatures of $-5^{\circ} \mathrm{C}$ and $-30^{\circ} \mathrm{C}$ for condensed water content in the range of 0.25 to $3 \mathrm{~g} \mathrm{~m}^{-3}$.

At the lower temperature, measurement uncertainty is below $20 \%$ when the condensed water content is above $0.14 \mathrm{~g} \mathrm{~m}^{-3}$. In warm air of $-5^{\circ} \mathrm{C}$ this is only the case above a CWC of $0.93 \mathrm{~g} \mathrm{~m}^{-3}$. Due to the high contributions of humidity measurement and inlet area uncertainty, the measurements of the total mass flow and IWT airspeed only marginally contribute to the overall uncertainty.

To validate the stated first-order analytic CWC uncertainties, a Monte Carlo method (Joint Committee for Guides in Metrology, 2008b) was applied. The method takes into account and propagates the assumed uncertainty distributions of the input quantities. As the TW inlet diameter is assumed to be within the measured and specified bounds with uniform probability (cf. Table E1), analytic and numeric uncertainties are expected to differ at high CWC where the inlet diameter contribution dominates. The numerically calculated shortest $95 \%$ coverage intervals attained with the Monte Carlo method lie within the analytic interval over the whole range of interest (cf. Appendix G, Fig. G1). Hence, the presented analytic uncertainties may be taken as upper bounds to a more realistic estimation of the uncertainty.

\section{Icing wind tunnel probe intercomparison}

The photoacoustic hygrometer in combination with the IKP was used for TW measurement during a water content probe intercomparison campaign at the RTA Rail Tech Arsenal Fahrzeugversuchsanlage GmbH (RTA) icing wind tunnel. The closed-circuit IWT is capable of simulating air temperatures down to $-30^{\circ} \mathrm{C}$ and wind speeds up to $80 \mathrm{~m} \mathrm{~s}^{-1}$ in a test section of $(3.5 \times 2.5 \times 3) \mathrm{m}$ (width $\times$ height $\times$ length $)$ 
at local ambient pressure. Test conditions included freezing drizzle and rain icing conditions with bimodal particle size distributions (in close agreement to EASA CS-25 Appendix O) and with MVDs of approximately $100 \mu \mathrm{m}$ and $550 \mu \mathrm{m}$ to $650 \mu \mathrm{m}$, respectively. Condensed water content during the probe intercomparison ranged from approximately 0.5 to $0.9 \mathrm{~g} \mathrm{~m}^{-3}$ for freezing drizzle and from 0.2 to $0.5 \mathrm{~g} \mathrm{~m}^{-3}$ for freezing rain conditions. Measurements in classical supercooled droplet icing conditions at higher cloud CWC had to be disregarded due to the already described oscillations observed in the TW measurements at high loads, suspected to be caused by temporary obstructions of the small diameter inlet. All measurements were conducted at a target static air temperature of $-5^{\circ} \mathrm{C}$ and wind speed of $60 \mathrm{~m} \mathrm{~s}^{-1}$. Freezing drizzle is created by 264 pneumatic atomizing nozzles mounted on horizontal spray bars placed approximately $12 \mathrm{~m}$ upstream from the test section. Freezing rain droplet size distributions with maximum diameters of approximately $1.5 \mathrm{~mm}$ were generated with an additional set of 12 rotating nozzles mounted on the IWT spray bar system (cf. Breitfuss et al., 2019).

The PA system was compared against a multi-element water content hot-wire probe (SEA, WCM-2000 Multi Element Water Content System) and an IKP from Cranfield University (CU-IKP; Bansmer et al., 2018), which utilizes commercial NDIR sensor-based hygrometers for simultaneous BWV and isokinetic TW measurement via backward- and forward-facing inlets and was specifically designed for high water content IWT measurement. All probes were mounted side by side on a horizontal splitter-plate-like panel with the probe inlets positioned at the approximate vertical center of the test section (cf. Fig. 11), and the measurements with the probes were conducted simultaneously. In the relevant area of the test section, LWC spatial cloud uniformity of the IWT is assumed to be better than $\pm 10 \%$ and $\pm 15 \%$ for freezing drizzle and freezing rain, respectively. The spatial cloud uniformity was determined with an icing cloud calibration grid (Breitfuss et al., 2019) and is within the SAE ARP-5905 recommended maximum allowable deviation $( \pm 20 \%)$.

During the intercomparison, the PA hygrometer was primarily used for TWC measurement. Continuous background humidity measurement was thus performed with an external capacitive humidity sensor (E+E Elektronik, EE33) mounted to the IWT wall. The sensor (labeled IWT humidity rear) has a specified relative humidity and temperature measurement accuracy better than $\pm 2.3 \% \mathrm{RH}$ and $\pm 0.25^{\circ} \mathrm{C}$, respectively, and is located downstream from the PA system IKP at the rear end of the IWT. BWV concentrations measured by this sensor were time-shifted to correct for the time delay resulting from the displacement from the probe location. A second humidity sensor of the same type (IWT humidity front) is placed at the test section but is not directly exposed to the main IWT air flow. This sensor is not used for evaluation but gives an indication of the true background humidity at the sampling point of the hygrometer.

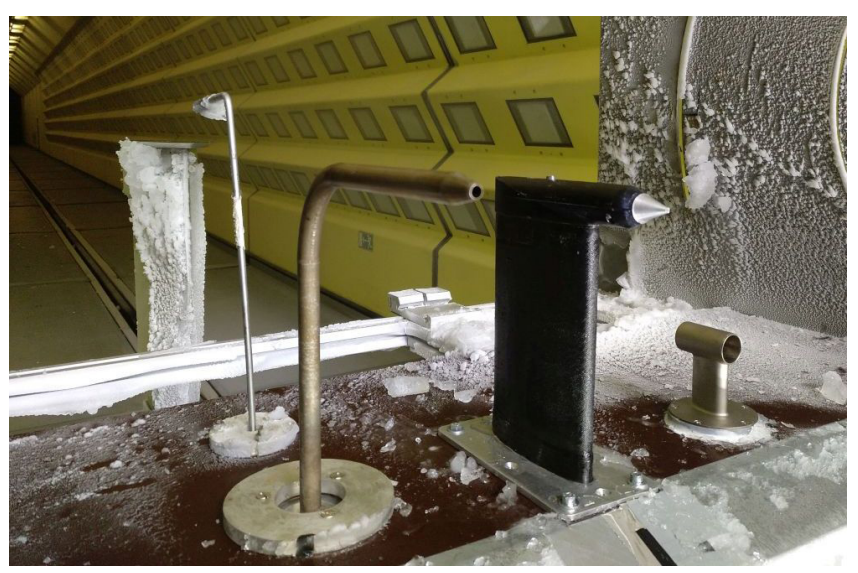

Figure 11. Positioning of the water content probes mounted on the splitter-plate-like panel in the RTA icing wind tunnel test section. Viewing direction is in the direction of flow. From left to right: Cranfield University IKP TW and backward-facing BWV inlet, PA hygrometer IKP, and SEA WCM-2000.

Figures 12 and 13 show two measurements in freezing rain with a drop MVD of approximately $550 \mu \mathrm{m}$. The upper panels show the TW and BWV mole fractions measured by the PA system and the CU-IKP together with background humidities measured by both IWT humidity sensors over time. The lower panels of Figs. 12 and 13 show the corresponding derived CWC for the PA system and the CU-IKP as well as the measured CWC by the multi-element hot-wire instrument. Activation of the IWT spray system is indicated by a calculated theoretical condensed water content (IWT spray), which, however, is known to underestimate the true CWC in SLD icing conditions. The high dispersion in the PA signal during cloud measurement is a result of the low averaging effect of the small probe TW inlet area in combination with the fast response time of the hygrometer $\left(\tau_{63}<2 \mathrm{~s}\right)$. Collection efficiency was assumed to be $100 \%$ for the evaluation, as the error is assumed to be below $1 \%$ for the SLD size distributions (cf. Sect. 4.3).

The external background humidity reference (IWT humidity rear) can be seen to correlate well with the PA system total water measurement when the spray system is inactive (cloudfree air). Nevertheless, considerable offset (several hundred ppm) was measured in all conditions and was therefore subtracted for the estimation of the condensed water content. Points in time of the $10 \mathrm{~s}$ offset calculation period are indicated with arrows in Figs. 12b and 13b. The observable offset is mainly attributed to the humidity sensor accuracy and to gradients in the IWT air temperature and saturation between the measurement locations.

The CU-IKP likewise indicated a steady offset of approximately $100 \mathrm{ppm}$ between the TW and BWV measurements when the spray system was inactive. This difference may have resulted from differing sensitivities or zero offset drift of the hygrometer channels and is corrected in a similar man- 


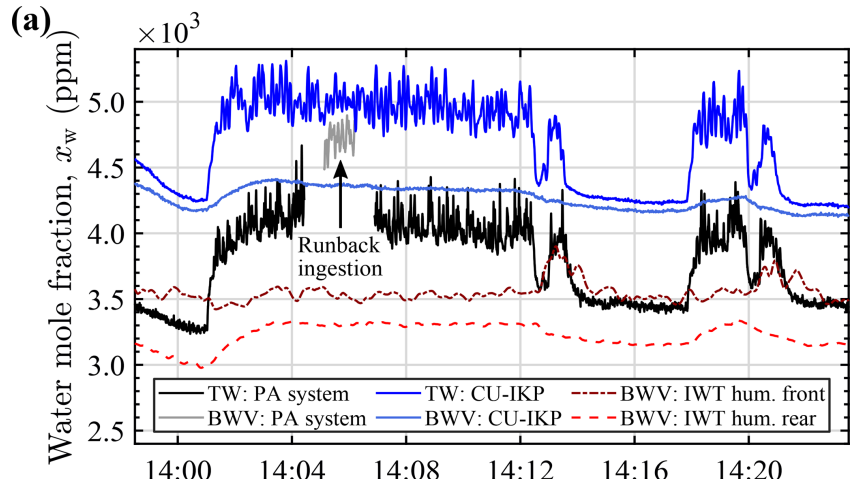

(b)

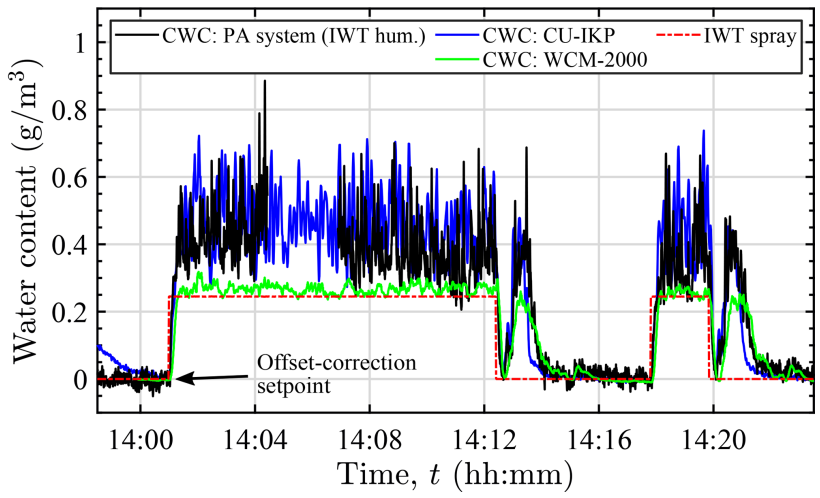

Figure 12. Water content measurements in freezing rain with a drop MVD of $550 \mu \mathrm{m}$ at $-5^{\circ} \mathrm{C}$ and $60 \mathrm{~m} \mathrm{~s}^{-1}$. (a) PA instrument and CUIKP TW and BWV mole fractions (erroneous PA instrument BWV sampling perpendicular to flow), together with BWV mole fractions calculated from the IWT humidity measurements. (b) CWC determined by the PA system (in combination with IWT humidity rear), the CU-IKP, and the hot-wire probe (WCM-2000). Spray activation is indicated by IWT spray.

ner as with the PA system. Additionally, as the CU-IKP has not been calibrated for absolute measurement and the NDIR gas analyzer was used without continuous reference measurement, exhibiting simultaneous but similar drift of both channels, measured concentrations were larger than determined by the IWT humidity sensors and the PA system. For some measurements, the difference between PA system and CU-IKP exceeded $2000 \mathrm{ppm}$. As large parts of humidities measured by the CU-IKP are in excess of the saturation mole fraction with respect to supercooled liquid (even well before activation of the spray), it is concluded that the calculated CU-IKP values overestimate true absolute TW and BWV content. Effects on CWC derivation, however, are mitigated by the expected similar drift of both channels and the primarily differential nature of $\mathrm{CWC}$ measurement.

Background humidity measurement with the PA instrument's BWV inlet port oriented perpendicular to the direction of flow resulted in highly elevated BWV levels (Fig. 12a) due to ingestion of runback water or sampling of air from the humidified thermal boundary layer of the heated probe. (a)

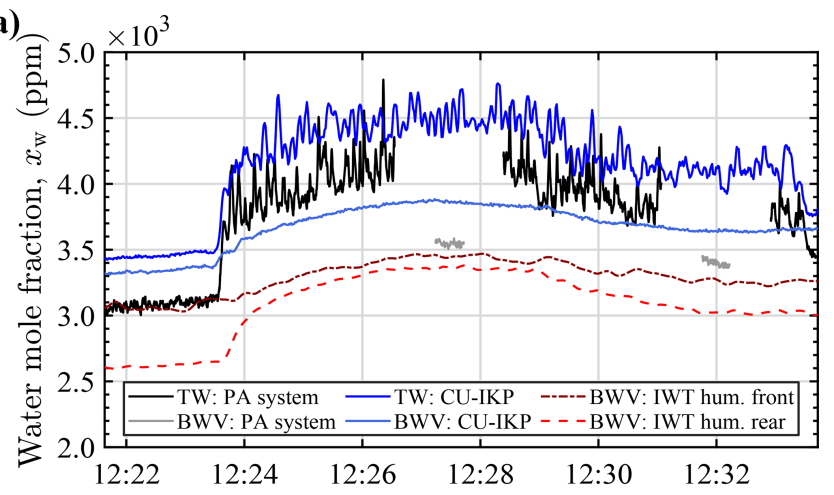

(b)

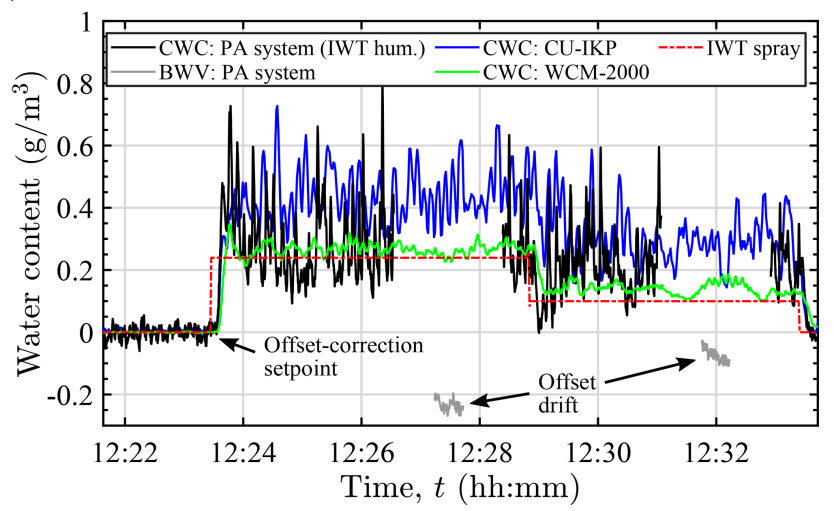

Figure 13. Water content measurement in freezing rain (MVD of $550 \mu \mathrm{m},-5^{\circ} \mathrm{C}, 60 \mathrm{~m} \mathrm{~s}^{-1}$ ) showing underestimated $\mathrm{CWC}$ due to significant background humidity offset drift. (a) PA instrument and CU-IKP TW and BWV mole fraction (extended PA instrument probe $\mathrm{BWV}$ inlet), together with $\mathrm{BWV}$ mole fractions calculated from the IWT humidity measurements. (b) CWC determined by the PA system (in combination with IWT humidity rear), the CU-IKP, and the hot-wire probe (WCM-2000). BWV: PA system shows the residual background offset between the PA system's BWV measurement and IWT humidity rear after offset correction. Spray activation is indicated by IWT spray.

Therefore, the latter half of the measurements was conducted with the probe BWV inlet extended by a backward-oriented tubing, which enabled intermittent and more reliable background humidity measurement in icing conditions. Differences (residuals) in background humidities measured by the PA system with the modified BWV inlet and the reference humidity sensor were used to identify measurements exhibiting considerable background humidity offset drift (cf. Fig. 13a and b), which were subsequently excluded from further evaluation. Dissimilar variations in the air temperature and saturation at the two separate background humidity measurement locations are assumed to be the main cause of the observed drift in the offset, as variations in the temperature difference between the two locations on the order of some tenths of degrees Celsius have frequently been encountered during measurement. For saturated air around $-5^{\circ} \mathrm{C}$ these temperature differences may have resulted in background 


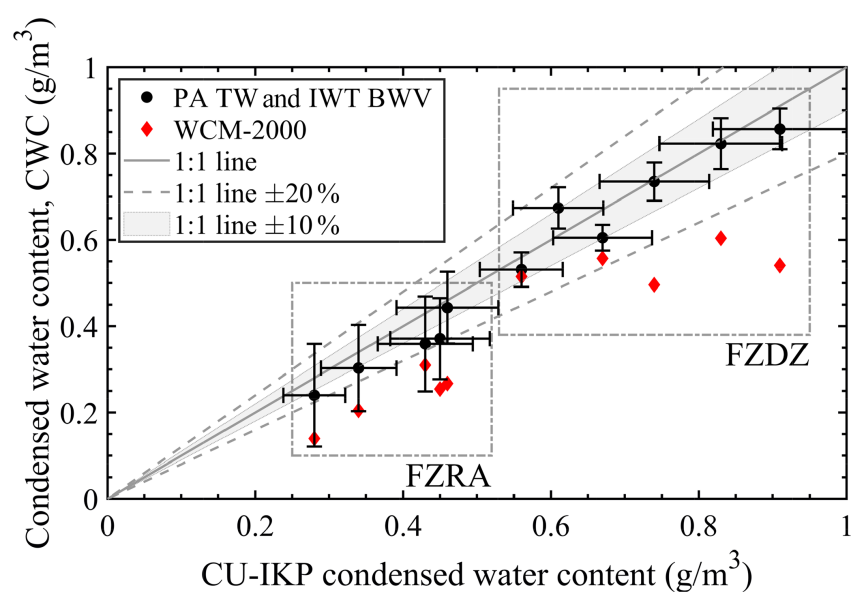

Figure 14. Mean measured CWC of the PA system in combination with the IWT background humidity measurement and of the hot-wire probe (WCM-2000) over the CWC measured by the Cranfield University IKP (CU-IKP). Dash-dotted rectangular boxes in the figure mark measurements of freezing rain (FZRA) and freezing drizzle (FZDZ) with MVDs of approximately $550 \mu \mathrm{m}$ to $650 \mu \mathrm{m}$ and $100 \mu \mathrm{m}$, respectively. Vertical error bars mark the standard deviations of the measurements. Horizontal error bars indicate the IWT cloud LWC uniformity $( \pm 15 \%$ and $\pm 10 \%$ for freezing drizzle and freezing rain, respectively).

water content differences and observable offset drifts on the order of some tenths of $\mathrm{g} \mathrm{m}^{-3}$. Due to the dynamic behavior of the background humidity, estimated offset drifts of up to $0.1 \mathrm{~g} \mathrm{~m}^{-3}$ could not be reliably detected with the described method and may have resulted in equivalent CWC measurement errors. For the water content encountered during the intercomparison, this may have resulted in relative errors of $11 \%$ to $36 \%$ for the highest and the lowest CWC, respectively.

Figure 14 finally shows the comparison of the mean CWC measured by all probes in conditions of freezing drizzle and freezing rain. Condensed water content determined with the PA system and the hot-wire probe are plotted over the mean CWC measured by the Cranfield University IKP, as the device was assumed to be the reference due to its superior probe design and the simultaneous background and TW measurement.

Precision of the presented measurements heavily depends on the stability of the background humidity during total water content measurement with the PA system and the correct identification of background humidity drifts. Although the measurement uncertainty cannot be quantified for the applied method of BWV estimation at the location of the IKP, the CWC derived from the PA system TW measurement is shown to agree within $\pm 20 \%$ of the reference measurement for conditions of freezing drizzle or rain. Condensed water content determined in freezing drizzle are within $\pm 10 \%$ of the reference (best-fit slope of 0.98).
Total condensed water content determined by the hotwire instrument was continuously below the CWC measured by the CU-IKP. This underestimation is partly attributed to splashing of large droplets from the hot-wire sensor element (cylindrical half-pipe facing in the direction of flow) but is larger than is anticipated for freezing drizzle cloud droplet distributions (Steen et al., 2016) and may indicate the advantages of isokinetic evaporator probes for CWC measurement in these conditions. A detailed analysis of the severe differences is outside the scope of this work. However, measured deviations from the reference IKP may also be attributable to spatial IWT cloud non-uniformity for all systems. Accuracy of PA system CWC measurement is additionally decreased by the high absolute background humidity present at the relatively warm IWT temperature during the measurements (cf. Sect. 4.3).

\section{Conclusions and outlook}

In this work, a hygrometer based on intensity-modulated photoacoustic spectroscopy with a near-infrared laser diode was developed and combined with a two-pressure humidity generator and an isokinetic evaporator probe to provide a new instrument capable of measuring total or background water content in simulated atmospheric icing conditions. The dynamic range of the single-wavelength PA hygrometer was shown to encompass water content occurring in SLD, mixedphase, and high IWC environments, where classical water content probes are associated with lower accuracy. Laboratory calibration of the hygrometer using the instrument's calibration unit displayed a $1 \mathrm{~s}$ integration time limit of detection of $23 \mathrm{ppm}$ and an accuracy (95\% coverage) better than $2.5 \%$ to $3.3 \%$ in the range of $512 \mathrm{ppm}$ to $12361 \mathrm{ppm}$ at standard pressure. The range corresponds to saturated sea-level cloudfree air at $-30^{\circ} \mathrm{C}$ and a CWC of $5 \mathrm{~g} \mathrm{~m}^{-3}$ in saturated $0{ }^{\circ} \mathrm{C}$ air. Since the determined accuracy is dominated by the uncertainty of the built-in humidity reference, further improvement of the hygrometer's measurement uncertainty may be achieved by using an independent traceable calibration.

For CWC measurements, a major contribution to the overall measurement uncertainty is associated with the small diameter TW inlet of the IKP $(3.3 \mathrm{~mm})$, which currently constrains the device uncertainty ( $95 \%$ coverage) to above $10 \%$ in all conditions. The small diameter is also suspected to cause temporary accumulation of water or ice in the inlet at high CWC loads. To further decrease the overall measurement uncertainty to the level of the hygrometer uncertainty, a redesign of the IKP inlet is the focus of ongoing research. The isokinetic aspiration efficiency of the probe at wind tunnel airspeeds above $60 \mathrm{~m} \mathrm{~s}^{-1}$ was determined by numerical means and near standard pressures and was shown to lie above $88 \%$ for droplets of any size and above $99 \%$ for droplets with diameters greater than $40 \mu \mathrm{m}$. From the determined size-dependent collection efficiency, a bias of less than 
$1 \%$ can be inferred for CWC measurement in absence of detailed droplet size distribution data in conditions of freezing drizzle or rain (EASA CS-25 Appendix O).

Uncertainty considerations showed that despite the current limitations given by the IKP inlet, an accuracy better than $20 \%$ is achieved by the instrument for CWC above $0.14 \mathrm{~g} \mathrm{~m}^{-3}$ in cold air $\left(-30^{\circ} \mathrm{C}\right)$ and when combined with a suitable background humidity measurement. For higher condensed water content, measurement accuracy further improves. In saturated warm air $\left(-5^{\circ} \mathrm{C}\right)$ the hygrometer uncertainty currently limits practical measurement to condensed water content above $0.9 \mathrm{~g} \mathrm{~m}^{-3}$. With additional adaptations of the TW inlet and improvement of the calibration process, further extension of the useful operating range to lower water content is expected. It has to be noted that the determined measurement uncertainty is higher than the $\pm 10 \%$ LWC measurement instrumentation maximum uncertainty demanded by the SAE ARP-5905, which, however, was defined for classical icing conditions (EASA CS-25 Appendix C) and may be increased in a similar recommended practice for the particularly challenging measurement in SLD icing conditions (SAE AIR-6341, 2015).

The system's TWC measurement capability was deployed in a CWC measurement intercomparison with a reference IKP instrument in freezing drizzle and rain conditions in the RTA icing wind tunnel. Background humidity had to be estimated independently by an external humidity sensor, which, together with the necessary method of offset correction, was determined to limit achievable measurement precision for the chosen setup. Measurements performed in warm air freezing drizzle and rain conditions with MVDs from 100 to $650 \mu \mathrm{m}$, however, showed a CWC agreement of the two IKPs within $\pm 20 \%$ for water content in the range of 0.3 to $0.9 \mathrm{~g} \mathrm{~m}^{-3}$. This is also within the recommended maximum LWC spatial deviation allowed by the SAE ARP-5905 $( \pm 20 \%)$. 


\section{Appendix A: Hygrometer pressure dependence}

The optimum operating point of the hygrometer in terms of cell pressure was determined from PA signal measurements acquired with humidified air at a constant water vapor mole fraction of 18760(120) ppm (cf. Fig. A1). As the measured signal, to a first approximation, is proportional to the hygrometer sensitivity, maximum sensitivity can be seen to be achieved towards high cell pressures. Decreasing sensitivity towards lower pressures is mainly a result of decreasing photoacoustic conversion efficiency (Lang et al., 2020) but may also be caused by a lowered sensitivity of the microphone or a lowered overlap of the laser optical emission spectrum with the (narrowing) water vapor absorption line (Bozóki et al., 2003). Signal-to-noise ratios calculated from the measured signals and the noise determined during background signal measurement indicate an optimum operating pressure around $850 \mathrm{hPa}$ (cf. Fig. A1). By comparison of the noise level determined with and without flow during background signal measurement, noise at low pressures could mainly be attributed to flow noise, which increases with decreasing cell pressure, presumably due to the position of the valve of the pressure controller upstream of the cell.

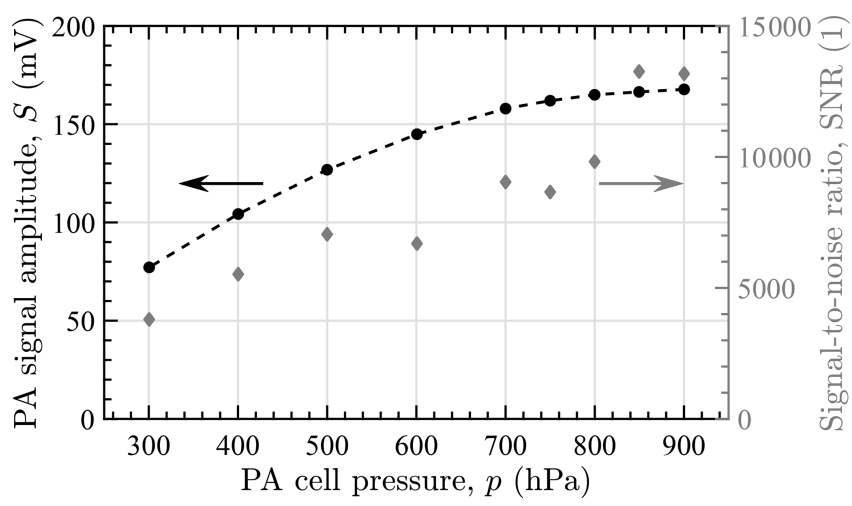

Figure A1. PA signal and signal-to-noise ratio as a function of the pressure of the PA cell operated at $35^{\circ} \mathrm{C}$. Signal measurements were performed with humidified air at a water vapor mole fraction of $18760(120) \mathrm{ppm}$ and with an averaging time of $1 \mathrm{~s}$. Noise used in the SNR calculation was determined from background signal measurements.

\section{Appendix B: Photoacoustic background signal correction}

The signal returned by the PA hygrometer is the lock-in signal $\boldsymbol{S}_{\boldsymbol{m}}=\left(S_{m, I}, S_{m, Q}\right)^{T}$, where $I$ and $Q$ denote the in-phase and quadrature components of the lock-in amplifier, respectively. Prior to each calibration, a background photoacoustic signal, $S_{\mathrm{BG}}=\left(S_{\mathrm{BG}, I}, S_{\mathrm{BG}, Q}\right)^{T}$ is recorded after flushing the PA cell with the zero air until a stable reading is attained.
The photoacoustic amplitude of all subsequent calibration or water content measurements is calculated on the digital signal processing unit of the hygrometer after phase-correct subtraction of the mean of the recorded PA background signal:

$$
\begin{aligned}
S & =\left\|\boldsymbol{S}_{m}-\overline{\boldsymbol{S}}_{\mathrm{BG}}\right\| \\
& =\sqrt{\left(S_{m, I}-\bar{S}_{\mathrm{BG}, I}\right)^{2}+\left(S_{m, Q}-\bar{S}_{\mathrm{BG}, Q}\right)^{2}} .
\end{aligned}
$$

\section{Appendix C: Calculation of inlet efficiencies, Stokes number, and stopping distance}

The aspiration efficiency $\eta_{\text {asp }}$ of particles at a given particle size $d_{\mathrm{p}}$ is given by the particle mass concentration in the air entering the inlet divided by the ambient mass concentration at that size (Belyaev and Levin, 1974),

$\eta_{\text {asp }}\left(d_{\mathrm{p}}\right)=\frac{\mathrm{CWC}_{\mathrm{i}}\left(d_{\mathrm{p}}\right)}{\operatorname{CWC}\left(d_{\mathrm{p}}\right)}$,

and may be written in terms of the limiting area $A_{\text {lim }}$ in front of the inlet, within which all trajectories of sampled particles begin, and the freestream to mean sampling velocity ratio $U_{\mathrm{a}} / \bar{U}_{\mathrm{s}}$ :

$\eta_{\text {asp }}\left(d_{\mathrm{p}}\right)=\frac{A_{\text {lim }}\left(d_{\mathrm{p}}\right)}{A_{\text {inlet }}} \cdot \frac{U_{\mathrm{a}}}{\bar{U}_{\mathrm{s}}}=\frac{E\left(d_{\mathrm{p}}\right)}{\mathrm{IKF}}$.

Here, $E=A_{\lim } / A_{\text {inlet }}$ is the particle size-dependent collection efficiency and IKF $=\bar{U}_{\mathrm{s}} / U_{\mathrm{a}}$ is the isokinetic factor.

For the evaluation of the collection efficiencies, the particle Stokes number $S t_{\mathrm{p}}$ is calculated according to Kulkarni et al. (2011):

$S t_{\mathrm{p}}=\frac{\rho_{\mathrm{p}} d_{\mathrm{p}}^{2} U_{\mathrm{p}} C_{\mathrm{c}}}{18 \eta d_{\text {inlet }}}$,

where $\rho_{\mathrm{p}}$ is the droplet density calculated for supercooled liquid water (Hare and Sorensen, 1987), $d_{\mathrm{p}}$ is the droplet diameter, $U_{\mathrm{p}}$ is the initial droplet velocity equal to the freestream airspeed $U_{\mathrm{a}}, C_{\mathrm{c}}$ is the Cunningham slip correction, $\eta$ is the air dynamic viscosity, and $d_{\text {inlet }}$ is the probe inlet diameter.

The Cunningham slip correction for droplets is calculated by

$C_{\mathrm{c}}=1+\frac{2 \lambda}{d_{\mathrm{p}}}\left[1.207+0.440 \exp \left(-0.596 d_{\mathrm{p}} /(2 \lambda)\right)\right]$

(Allen and Raabe, 1985; Rader, 1990), where the mean free path $\lambda$ according to Willeke (1976) is given by

$\lambda=\lambda_{\mathrm{r}}\left(\frac{101 \cdot 10^{3}}{p_{\mathrm{a}}}\right)\left(\frac{T_{\mathrm{a}}}{293}\right)\left(\frac{1+101 / 293}{1+101 / T_{\mathrm{a}}}\right)$.

The air dynamic viscosity is calculated by

$\eta=\eta_{\mathrm{r}}\left(\frac{T_{\mathrm{r}}+S_{u}}{T_{\mathrm{a}}+S_{u}}\right)\left(\frac{T_{\mathrm{a}}}{T_{\mathrm{r}}}\right)^{3 / 2}$ 
(Kulkarni et al., 2011), where the reference viscosity $\eta_{\mathrm{r}}$ is $18.33 \times 10^{-6} \mathrm{Pas}$ and the Sutherland interpolation constant $S_{u}$ is $110.4 \mathrm{~K}$ at the reference temperature $T_{\mathrm{r}}$ of $293 \mathrm{~K}$.

The particle stopping distance $S_{\mathrm{p}}$ for droplet or particle Reynolds numbers $R e_{\mathrm{p}}$ in the range of 1 to 400 is calculated with the correlation obtained by Mercer (1973):

$S_{\mathrm{p}}=\frac{\rho_{\mathrm{p}} d_{\mathrm{p}}}{\rho_{\mathrm{a}}}\left(R e_{\mathrm{p}}^{1 / 3}-\sqrt{6} \arctan \left(\frac{R e_{\mathrm{p}}^{2 / 3}}{\sqrt{6}}\right)\right)$.

\section{Appendix D: Hygrometer temporal response}

Figure D1 shows a sequence of recovery and response time measurements, performed with the described instrument by alternately sampling humidified and ambient air.

(a)

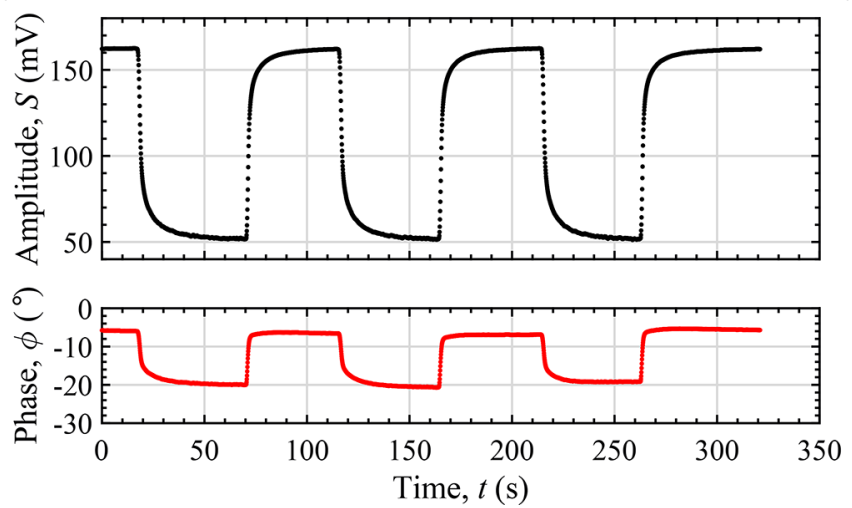

(b)

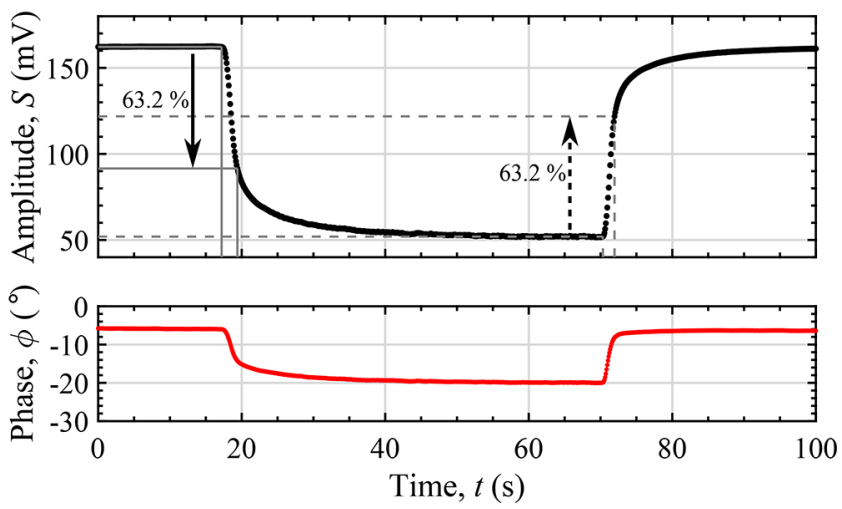

Figure D1. (a) Background corrected photoacoustic amplitude and phase during a sequence of recovery and response time measurements, performed by alternately sampling humidified and ambient air with water vapor mole fractions of 18750 and $5570 \mathrm{ppm}$, respectively. A lock-in integration time of $1 \mathrm{~s}$ was used. (b) First segment of (a) with indicated PA signal levels used for the determination of the $63.2 \%$ response and recovery times. 


\section{Appendix E: Summary of input uncertainties}

Table E1 summarizes individual uncertainty contributions to the overall instrument CWC measurement uncertainty.

\section{Appendix F: Hygrometer uncertainty}

The theoretical background corrected lock-in signal amplitude for a given water vapor mole fraction in air $x_{\mathrm{w}}$ and a parameter set $\boldsymbol{b}$ may be written as $S=f\left(x_{\mathrm{w}}, \boldsymbol{b}\right)$ (Lang et al., 2020). To determine the parameters in the calibration function with the least-squares method (Eq. 2), while considering the calibration humidity uncertainty $u\left(x_{\mathrm{w}, i}\right)$, the inverse function $x_{\mathrm{w}}=f^{-1}(S, \boldsymbol{b})$ is required. As no closed-form expression for $x_{\mathrm{w}}$ can be found, the water vapor mole fraction is obtained by numerically finding the root of

$g\left(S, x_{\mathrm{w}}, \boldsymbol{b}\right)=S-f\left(x_{\mathrm{w}}, \boldsymbol{b}\right)$

for a measured signal amplitude and a given set of parameters:

$x_{\mathrm{w}}=f^{-1}(S, \boldsymbol{b})=\{x \mid g(S, x, \boldsymbol{b})=0\}$.

The measurement uncertainty of the PA hygrometer $u\left(x_{\mathrm{w}}\right)$ is then evaluated from Eq. (F2) by combining the uncertainties of the measurement signal amplitude $u(S)$ and the correlated parameters determined from calibration, following the GUM (Joint Committee for Guides in Metrology, 2008a):

$$
\begin{aligned}
u^{2}\left(x_{\mathrm{w}}\right) & =\left(\frac{\partial f^{-1}}{\partial S}\right)^{2} u^{2}(S) \\
& +\sum_{i=1}^{5} \sum_{j=1}^{5} \frac{\partial f^{-1}}{\partial b_{i}} \frac{\partial f^{-1}}{\partial b_{j}} u\left(b_{i}, b_{j}\right),
\end{aligned}
$$

where $u\left(b_{i}, b_{j}\right)$ is the covariance of the fit parameters $b_{i}$ and $b_{j} . u\left(b_{i}, b_{i}\right)=u^{2}\left(b_{i}\right)$ is the variance of coefficient $b_{i}$.

The uncertainty in the measured signal amplitude is estimated from the Allan deviation analysis and is taken to be equivalent to the signal noise at the measurement integration time of $1 \mathrm{~s}$.

The sensitivity coefficients in Eq. (F3), i.e., the partial derivatives of $f^{-1}$ with respect to the PA signal amplitude and the calibration function parameters, are calculated from Eqs. (F1) and (F2) by using standard rules of calculus (Lira, 2002):

$$
\begin{gathered}
\frac{\partial f^{-1}}{\partial S}=-\frac{\partial g / \partial S}{\partial g / \partial x_{\mathrm{w}}}=\frac{1}{\partial f / \partial x_{\mathrm{w}}}, \\
\frac{\partial f^{-1}}{\partial b_{i}}=-\frac{\partial g / \partial b_{i}}{\partial g / \partial x_{\mathrm{w}}}=-\frac{\partial f / \partial b_{i}}{\partial f / \partial x_{\mathrm{w}}} .
\end{gathered}
$$

Errors introduced by finding the root in Eq. (F2) are assumed to be negligible due to the high accuracy of the numerical solver with the chosen tolerance level.

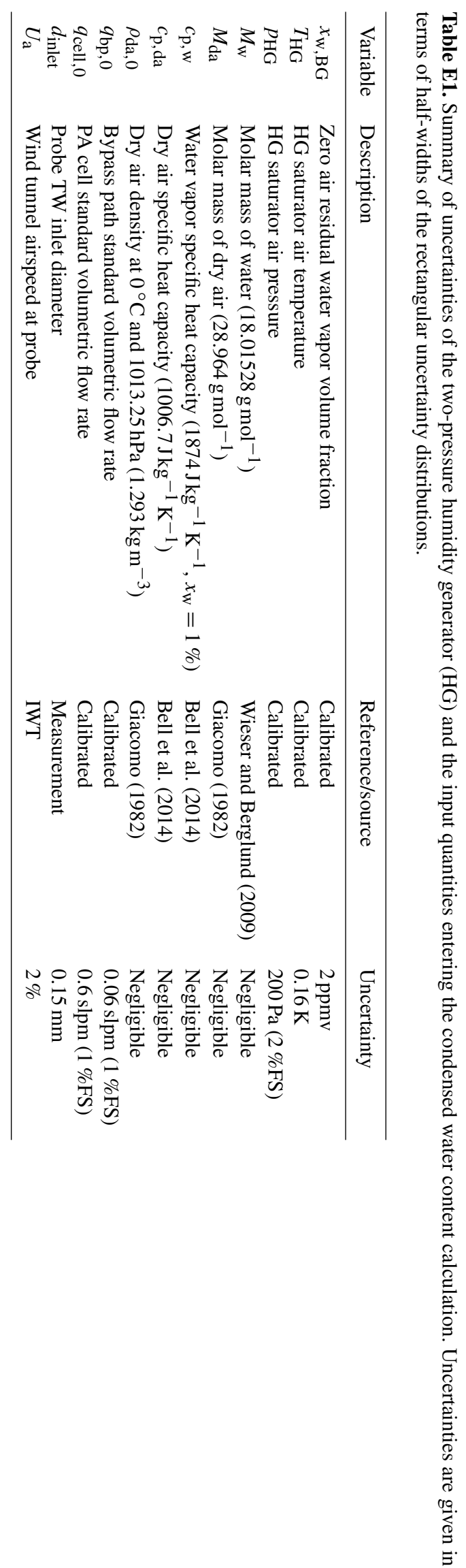

https://doi.org/10.5194/amt-14-2477-2021 


\section{Appendix G: Numerical CWC uncertainty evaluation}

Figure G1 shows the comparison of the $95 \%$ coverage intervals of the CWC measurement uncertainty calculated with the first-order analytical and the Monte Carlo method for an IWT static air temperature of $-30^{\circ} \mathrm{C}$ and an airspeed of $60 \mathrm{~m} \mathrm{~s}^{-1}$. Uncertainties are given relative to the actual CWC. The shortest intervals obtained by the Monte Carlo method can be seen to lie within the analytical intervals over the whole CWC range of interest.

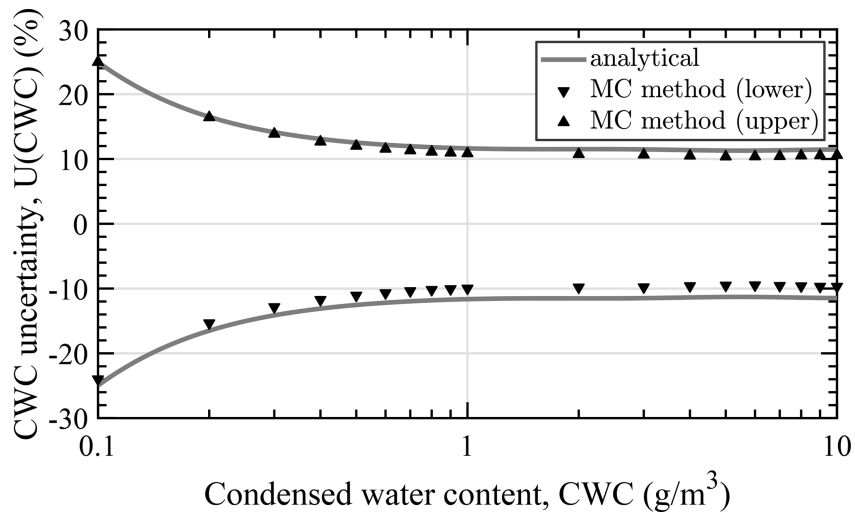

Figure G1. $95 \%$ coverage intervals of the CWC measurement uncertainty calculated with the first-order analytical and the Monte Carlo (MC) method. Uncertainties are given relative to the actual CWC. Icing wind tunnel static air temperature, pressure, and airspeed are set to $-30^{\circ} \mathrm{C}, 1013.25 \mathrm{hPa}$, and $60 \mathrm{~m} \mathrm{~s}^{-1}$, respectively, and the ambient air is assumed to be fully saturated with respect to supercooled liquid water. Monte Carlo intervals are the shortest (non-symmetric) $95 \%$ intervals indicated by the lower and upper bounds. 
Data availability. All data acquired and used for the photoacoustic hygrometer calibration and characterization are freely available from the corresponding author upon request.

Author contributions. The conceptualization was performed by $\mathrm{BL}, \mathrm{WB}, \mathrm{WH}$, and $\mathrm{AB}$. The methodology and investigation were completed by BL, PB, WB, AT, and HP. The software and material preparation were performed by BL, WB, SS, and HP. BL drafted the original manuscript, which was reviewed and edited by all authors. Funding was acquired by AT, AB, and WH. Resources were provided by $A B, A K$, and $\mathrm{WH}$. Supervision was the responsibility of $\mathrm{AB}$ and $\mathrm{WH}$, and project administration by $\mathrm{AB}, \mathrm{AK}$, and $\mathrm{WH}$.

Competing interests. The authors declare that they have no conflict of interest.

Financial support. This work has been partly funded by the Austrian Aeronautics Programme TAKE OFF of the Federal Ministry of Transport, Innovation and Technology (BMVIT), managed by the Österreichische Forschungsförderungsgesellschaft (FFG; Project number: 850457).

Review statement. This paper was edited by Szymon Malinowski and reviewed by two anonymous referees.

\section{References}

Allen, M. D. and Raabe, O. G.: Slip correction measurements of spherical solid aerosol particles in an improved millikan apparatus, Aerosol Sci. Tech., 4, 269-286, https://doi.org/10.1080/02786828508959055, 1985.

Bansmer, S. E., Baumert, A., Sattler, S., Knop, I., Leroy, D., Schwarzenboeck, A., Jurkat-Witschas, T., Voigt, C., Pervier, H., and Esposito, B.: Design, construction and commissioning of the Braunschweig Icing Wind Tunnel, Atmos. Meas. Tech., 11, 3221-3249, https://doi.org/10.5194/amt-11-3221-2018, 2018.

Bell, I. H., Wronski, J., Quoilin, S., and Lemort, V.: Pure and pseudo-pure fluid thermophysical property evaluation and the open-source thermophysical property library coolprop, Industrial and Engineering Chemistry Research, 53, 2498-2508, https://doi.org/10.1021/ie4033999, 2014.

Belyaev, S. P. and Levin, L. M.: Techniques for collection of representative aerosol samples, J. Aerosol Sci., 5, 325-338, https://doi.org/10.1016/0021-8502(74)90130-X, 1974.

Bernstein, B. C., Ratvasky, T. P., Miller, D. R., and McDonough, F.: Freezing Rain as an In-Flight Icing Hazard, Technical Report TM-2000-210058, NASA, Washington D.C., USA, 12 pp., 2000.

Besson, J.-P., Schilt, S., and Thévenaz, L.: Sub-ppm multigas photoacoustic sensor, Spectrochim. Acta A, 63, 899-904, https://doi.org/10.1016/j.saa.2005.10.034, 2006.

Bozóki, Z., Szakáll, M., Mohácsi, Á., Szabó, G., and Bor, Z.: Diode laser based photoacoustic humidity sensors, Sensor.
Actuat. B-Chem., 91, 219-226, https://doi.org/10.1016/S09254005(03)00120-5, 2003.

Bozóki, Z., Pogány, A., and Szabó, G.: Photoacoustic instruments for practical applications: Present, potentials, and future challenges, Appl. Spectrosc. Rev., 46, 1-37, https://doi.org/10.1080/05704928.2010.520178, 2011.

Breitegger, P. and Bergmann, A.: A Precise Gas Dilutor Based on Binary Weighted Critical Flows to Create $\mathrm{NO}_{2}$ Concentrations, Proceedings, 2, 998, https://doi.org/10.3390/proceedings2130998, 2018.

Breitfuss, W., Wannemacher, M., Knöbl, F., and Ferschitz, H.: Aerodynamic Comparison of Freezing Rain and Freezing Drizzle Conditions at the RTA Icing Wind Tunnel, SAE J.-Automot. Eng., 2, 245-255, https://doi.org/10.4271/2019-01-2023, 2019.

Chalmers, J., Davison, C., Macleod, J., Neuteboom, M., and Fuleki, D.: Icing Test and Measurement Capabilities of the NRC's Gas Turbine Laboratory, SAE J. Automot. Eng., SAE Technical Paper 2019-01-1943, https://doi.org/10.4271/2019-01-1943, 2019.

Cober, S., Bernstein, B., Jeck, R., Hill, E., Isaac, G., Riley, J., and Shah, A.: Data and Analysis for the Development of an Engineering Standard for Supercooled Large Drop Conditions, Technical Report, US Department of Transportation, Federal Aviation Administration, Washington DC, USA, 89 pp., 2009.

Cober, S. G., Isaac, G. A., Korolev, A. V., and Strapp, J. W.: Assessing cloud-phase conditions, J. Appl. Meteorol., 40, 1967-1983, https://doi.org/10.1175/15200450(2001)040<1967:ACPC>2.0.CO;2, 2001a.

Cober, S. G., Isaac, G. A., and Strapp, J. W.: Characterizations of aircraft icing environments that include supercooled large drops, J. Appl. Meteorol., 40, 1984-2002, https://doi.org/10.1175/15200450(2001)040<1984:COAIET>2.0.CO;2, 2001b.

Davis, S. M., Hallar, A. G., Avallone, L. M., and Engblom, W.: Measurement of total water with a tunable diode laser hygrometer: Inlet analysis, calibration procedure, and ice water content determination, J. Atmos. Ocean. Tech., 24, 463-475, https://doi.org/10.1175/JTECH1975.1, 2007.

Davison, C., MacLeod, J., Strapp, J., and Buttsworth, D.: Isokinetic Total Water Content Probe in a Naturally Aspirating Configuration: Initial Aerodynamic Design and Testing, in: Proceedings of the 46th AIAA Aerospace Sciences Meeting and Exhibit, Reston, USA, 7-10 January 2008, https://doi.org/10.2514/6.2008435, 2008.

Davison, C. R., Walter Strapp, J., Lilie, L., Ratvasky, T. P., and Dumont, C.: Isokinetic TWC evaporator probe: Calculations and systemic uncertainty analysis, in: Proceedings of the 8th AIAA Atmospheric and Space Environments Conference, Washington, D.C., 13-17 June 2016, https://doi.org/10.2514/6.20164060, 2016.

Dorsi, S. W., Kalnajs, L. E., Toohey, D. W., and Avallone, L. M.: A fiber-coupled laser hygrometer for airborne total water measurement, Atmos. Meas. Tech., 7, 215-223, https://doi.org/10.5194/amt-7-215-2014, 2014.

EASA CS-25: Certification Specifications and Acceptable Means of Compliance for Large Aeroplanes CS-25, Technical Report, European Aviation Safety Agency, Cologne, Germany, 1126 pp., 2020.

Emery, E. F., Miller, D. R., Plaskon, S. R., Strapp, W., and Lillie, L.: Ice particle impact on cloud water content instrumentation, 
in: Proceedings of the 42nd AIAA Aerospace Sciences Meeting and Exhibit, Reno, Nevada, 5-8 January 2004, 8387-8398, https://doi.org/10.2514/6.2004-731, 2004.

FAA CFR-25: US Code of Federal Regulations, Title 14, Part 25, Airworthiness Standards, Transport Category Airplanes, Federal Aviation Administration, Department of Transportation, USA, 2019.

Gent, R. W., Dart, N. P., and Cansdale, J. T.: Aircraft icing, Philos. T. R. Soc. A, 358, 2873-2911, https://doi.org/10.1098/rsta.2000.0689, 2000.

Giacomo, P.: Equation for the determination of the density of moist air (1981), Metrologia, 18, 33-40, https://doi.org/10.1088/00261394/18/1/006, 1982.

Gordon, I. E., Rothman, L. S., Hill, C., Kochanov, R. V., Tan, Y., Bernath, P. F., Birk, M., Boudon, V., Campargue, A., Chance, K. V., Drouin, B. J., Flaud, J. M., Gamache, R. R., Hodges, J. T., Jacquemart, D., Perevalov, V. I., Perrin, A., Shine, K. P., Smith, M. A., Tennyson, J., Toon, G. C., Tran, H., Tyuterev, V. G., Barbe, A., Császár, A. G., Devi, V. M., Furtenbacher, T., Harrison, J. J., Hartmann, J. M., Jolly, A., Johnson, T. J., Karman, T., Kleiner, I., Kyuberis, A. A., Loos, J., Lyulin, O. M., Massie, S. T., Mikhailenko, S. N., Moazzen-Ahmadi, N., Müller, H. S., Naumenko, O. V., Nikitin, A. V., Polyansky, O. L., Rey, M., Rotger, M., Sharpe, S. W., Sung, K., Starikova, E., Tashkun, S. A., Auwera, J. V., Wagner, G., Wilzewski, J., Wcisło, P., Yu, S., and Zak, E. J.: The HITRAN2016 molecular spectroscopic database, J. Quant. Spectrosc. Ra., 203, 3-69, https://doi.org/10.1016/j.jqsrt.2017.06.038, 2017.

Greenspan, L.: Functional equations for the enhancement factors for $\mathrm{CO}_{2}$-free moist air, J. Res. NBS A Phys. Ch., 80, 41-44, https://doi.org/10.6028/jres.080a.007, 1976.

Hardy, J. E., Hylton, J. O., and Mcknight, T. E.: Empirical correlations for thermal flowmeters covering a wide range of thermalphysical properties, National Conference of Standards Labs, Charlotte, NC, USA, 19-22 July 1999.

Hare, D. E. and Sorensen, C. M.: The density of supercooled water. II. Bulk samples cooled to the homogeneous nucleation limit, J. Chem. Phys., 87, 4840-4845, https://doi.org/10.1063/1.453710, 1987.

Hodgkinson, J. and Tatam, R. P.: Optical gas sensing: a review, Meas. Sci. Technol., 24, 012004, https://doi.org/10.1088/09570233/24/1/012004, 2013.

Isaac, G. A., Korolev, A. V., Strapp, J. W., Cober, S. G., Boudala, F. S., Marcotte, D., and Reich, V. L.: Assessing the collection efficiency of natural cloud particles impacting the Nevzorov total water content probe, in: Proceedings of the 44th AIAA Aerospace Sciences Meeting, Reno, Nevada, 9-12 January 2006, Reno, Nevada, 14846-14858, https://doi.org/10.2514/6.20061221, 2006.

Joint Committee for Guides in Metrology: Evaluation of measurement data - Guide to the expression of uncertainty in measurement, ISO/IEC GUIDE 98-3:2008, Uncertainty of measurement - Part 3: Guide to the expression of uncertainty in measurement (GUM:1995), International Organization for Standardization, Geneva, Switzerland, 2008a.

Joint Committee for Guides in Metrology: Evaluation of measurement data - Supplement 1 to the Guide to the expression of uncertainty in measurement - Propagation of distributions using a Monte Carlo method, ISO/IEC GUIDE 98-3:2008/SUPPL
1:2008, Uncertainty of measurement - Part 3: Guide to the expression of uncertainty in measurement (GUM:1995) - Supplement 1: Propagation of distributions using a Monte Carlo method, International Organization for Standardization, Geneva, Switzerland, 2008b.

Korolev, A., Strapp, J. W., Isaac, G. A., and Emery, E.: Improved airborne hot-wire measurements of ice water content in clouds, J. Atmos. Ocean. Tech., 30, 2121-2131, https://doi.org/10.1175/JTECH-D-13-00007.1, 2013.

Kosterev, A. A., Tittel, F. K., Knittel, T. S., Cowie, A., and Tate, J. D.: Trace Humidity Sensor based on Quartz-Enhanced Photoacoustic Spectroscopy, Laser Applications to Chemical, Security and Environmental Analysis 2006, Incline Village, Nevada United States, 5-9 February 2006, Paper ID: TuA2, https://doi.org/10.1364/LACSEA.2006.TuA2, 2006.

Krämer, M. and Afchine, A.: Sampling characteristics of inlets operated at low $U / U_{0}$ ratios: New insights from computational fluid dynamics (CFX) modeling, J. Aerosol Sci., 35, 683-694, https://doi.org/10.1016/j.jaerosci.2003.11.011, 2004.

Kulkarni, P., Baron, P. A., and Willeke, K.: Aerosol measurement: principles, techniques, and applications, John Wiley and Sons, Hoboken, New Jersey, USA, 2011.

Lang, B., Breitegger, P., Brunnhofer, G., Prats Valero, J., Schweighart, S., Klug, A., Hassler, W., and Bergmann, A.: Molecular relaxation effects on vibrational water vapor photoacoustic spectroscopy in air, Appl. Phys. B-Lasers O., 126, 1-18, https://doi.org/10.1007/s00340-020-7409-3, 2020.

Langridge, J. M., Richardson, M. S., Lack, D. A., Brock, C. A., and Murphy, D. M.: Limitations of the photoacoustic technique for aerosol absorption measurement at high relative humidity, Aerosol Sci. Tech., 47, 1163-1173, https://doi.org/10.1080/02786826.2013.827324, 2013.

LI-COR Inc.: Using the LI-830 and LI-850 Gas Analyzers, Technical Report, available at: https://www.licor.com/documents/ gz8gaf01s5vhvpl52xtmyr8mfoh5kwe8 (last access: 12 March 2021), 2020.

Lira, I.: Evaluating the Measurement Uncertainty, IOP Publishing, London, UK, 2002.

Mason, J. G., Strapp, J. W., and Chow, P.: The ice particle threat to engines in flight, in: Proceedings of the 44th AIAA Aerospace Sciences Meeting, Reno, Nevada, USA, 9-12 January 2006, 2445-2465, 2006.

Mercer, T. T.: Aerosol technology in hazard evaluation, Academic Press, New York, USA, https://doi.org/10.1016/00219797(74)90320-8, 1973.

Meyer, C. W., Hodges, J. T., Huang, P. H., Miller, W. W., Ripple, D. C., Scace, G. E., Gutierrez, C. M., and Gallagher, P.: Calibration of Hygrometers with the Hybrid Humidity Generator, National Institute of Standards and Technology, Gaithersburg, Maryland, USA, NIST SP 250-83, 48 pp., https://doi.org/10.6028/NIST.SP.250-83, 2008.

Orchard, D. M., Szilder, K., and Davison, C. R.: Design of an icing wind tunnel contraction for supercooled large drop conditions, in: 2018 Atmospheric and Space Environments Conference, Atlanta, Georgia, 25-29 June 2018, AIAA 2018-3185, https://doi.org/10.2514/6.2018-3185, 2018.

Orchard, D. M., Clark, C., and Chevrette, G.: Measurement of Liquid Water Content for Supercooled Large Drop Conditions in the NRC's Altitude Icing Wind Tunnel, in: SAE J.-Automot. 
Eng., Article ID: 2019-01-2007, https://doi.org/10.4271/201901-2007, 2019.

Politovich, M. K.: Aircraft icing caused by large supercooled droplets, J. Appl. Meteorol., 28, 856-868, https://doi.org/10.1175/15200450(1989)028<0856:AICBLS>2.0.CO;2, 1989.

Rader, D. J.: Momentum slip correction factor for small particles in nine common gases, J. Aerosol Sci., 21, 161-168, https://doi.org/10.1016/0021-8502(90)90001-E, 1990.

Rader, D. J. and Marple, V. A.: A study of the effects of anisokinetic sampling, Aerosol Sci. Tech., 8, 283-299, https://doi.org/10.1080/02786828808959190, 1988.

Ratvasky, T., Harrah, S., Strapp, J. W., Lilie, L., Proctor, F., Strickland, J., Hunt, P., Bedka, K., Diskin, G., Nowak, J. B., Bui, T. P., Bansemer, A., and Dumont, C.: Summary of the High Ice Water Content (HIWC) RADAR Flight Campaigns, SAE J.-Automot. Eng., Article ID: 2019-01-2027, https://doi.org/10.4271/201901-2027, 2019.

Riley, J. T.: Mixed-Phase Icing Conditions: A Review, Technical Report DOT/FAA/AR-98/76, US Department of Transportation Federal Aviation Administration, Washington DC, USA, 45 pp., 1998.

SAE AIR-6341: SLD capabilities of icing wind tunnels, SAE International, available at: https://www.sae.org/standards/content/ air6341/ (last access: 12 March 2021), 2015.

SAE ARP-5905: Calibration and Acceptance of Icing Wind Tunnels, SAE International, available at: https://www.sae.org/ standards/content/arp5905/ (last access: 12 March 2021), 2015.

Selamet, A. and Radavich, P. M.: The effect of length on the acoustic attenuation performance of concentric expansion chambers: An analytical, computational and experimental investigation, J. Sound Vib., 201, 407-426, https://doi.org/10.1006/jsvi.1996.0720, 1997.

Steen, L.-C. E., Ide, R. F., and Van Zante, J. F.: An assessment of the icing blade and the SEA multi-element sensor for liquid water content calibration of the NASA GRC icing research tunnel, in: Proceedings of the 8th AIAA Atmospheric and Space Environments Conference, Washington, D.C., USA 13-17 June 2016, AIAA 2016-4051, https://doi.org/10.2514/6.2016-4051, 2016.

Strapp, J., Lilie, L. E., Ratvasky, T. P., Davison, C., and Dumont, C.: Isokinetic TWC evaporator probe: Development of the IKP2 and performance testing for the HAIC-HIWC darwin 2014 and cayenne-2015 field campaigns, in: Proceedings of the 8th AIAA Atmospheric and Space Environments Conference, Washington, D.C., USA, 13-17 June 2016, AIAA 2016-4059, 1-28, https://doi.org/10.2514/6.2016-4059, 2016.

Strapp, J. W., Oldenburg, J., Ide, R., Lilie, L., Bacic, S., Vukovic, Z., Oleskiw, M., Miller, D., Emery, E., and Leone, G.: Wind tunnel measurements of the response of hot-wire liquid water content instruments to large droplets, J. Atmos. Ocean. Tech., 20, 791-806, https://doi.org/10.1175/15200426(2003)020<0791:WTMOTR>2.0.CO;2, 2003.
Szakáll, M., Bozóki, Z., Kraemer, M., Spelten, N., Moehler, O., and Schurath, U.: Evaluation of a Photoacoustic Detector for Water Vapor Measurements under Simulated Tropospheric/Lower Stratospheric Conditions, Environ. Sci. Technol., 35, 4881-4885, https://doi.org/10.1021/es015564x, 2001.

Szakáll, M., Varga, A., Pogány, A., Bozóki, Z., and Szabó, G.: Novel resonance profiling and tracking method for photoacoustic measurements, Appl. Phys. B, 94, 691-698, https://doi.org/10.1007/s00340-009-3391-5, 2009.

Tátrai, D., Bozóki, Z., Smit, H., Rolf, C., Spelten, N., Krämer, M., Filges, A., Gerbig, C., Gulyás, G., and Szabó, G.: Dualchannel photoacoustic hygrometer for airborne measurements: background, calibration, laboratory and in-flight intercomparison tests, Atmos. Meas. Tech., 8, 33-42, https://doi.org/10.5194/amt8-33-2015, 2015.

Van Zante, J. F., Ratvasky, T. P., Bencic, T. J., Challis, C. C., Timko, E. N., and Woike, M. R.: Update on the nasa glenn propulsion systems lab icing and ice crystal cloud characterization (2017), in: Proceedings of the 2018 Atmospheric and Space Environments Conference, Atlanta, Georgia, USA, 25-29 June 2018, 7783, https://doi.org/10.2514/6.2018-3969, 2018.

Vukits, T. J.: Overview and risk assessment of icing for transport category aircraft and components, in: Proceedings of the 40th AIAA Aerospace Sciences Meeting and Exhibit, Reno, Nevada, USA, 14-17 January 2002, Abstract ID: 2002-0811, https://doi.org/10.2514/6.2002-811, 2002.

Wagner, W. and Pruss, A.: International Equations for the Saturation Properties of Ordinary Water Substance, Revised According to the International Temperature Scale of 1990, J. Phys. Chem. Ref. Data, 22, 783-787, https://doi.org/10.1063/1.555926, 1993.

Werle, P., Mücke, R., and Slemr, F.: The limits of signal averaging in atmospheric trace-gas monitoring by tunable diode-laser absorption spectroscopy (TDLAS), Appl. Phys. B, 57, 131-139, https://doi.org/10.1007/BF00425997, 1993.

Wernecke, J. and Wernecke, R.: Industrial Moisture and Humidity Measurement: A Practical Guide, Wiley-VCH, Weinheim, Germany, 2013.

Wiederhold, P. R.: Water Vapor Measurement: Methods and Instrumentation, CRC Press, Boca Raton, Florida, USA, 1997.

Wieser, M. E. and Berglund, M.: Atomic weights of the elements 2007 (IUPAC technical report), Pure Appl. Chem., 81, 21312156, https://doi.org/10.1351/PAC-REP-09-08-03, 2009.

Willeke, K.: Temperature dependence of particle slip in a gaseous medium, J. Aerosol Sci., 7, 381-387, https://doi.org/10.1016/0021-8502(76)90024-0, 1976.

Zuckerwar, A. J.: Handbook of the Speed of Sound in Real Gases, Academic Press, San Diego, California, USA, 2002. 